\title{
Thermodynamic and experimental evaluation of a cloud chamber for ultrafine particle detection
}

\author{
Wenming Yang ${ }^{1,2}$, and Adam M. Boies ${ }^{2 *}$ \\ ${ }^{1}$ School of Mechanical Engineering, University of Science and Technology Beijing, Beijing \\ 100083, China \\ ${ }^{2}$ Department of Engineering, University of Cambridge, Cambridge, CB2 1PZ, United Kingdom \\ *E-mail: amb233@cam.ac.uk
}

\begin{abstract}
Particle sensing based on condensational growth has long been the basis for robust nanoparticle measurement. Increasingly cloud chamber devices offer the potential for low-cost and portable measurement when operated semi-continuously with relatively small system volumes. Models based on isentropic and isenthalpic expansion are derived to predict the time evolution of temperature, saturation ratio, particle growth, and resultant light extinction in cloud chambers. A laboratory cloud chamber is fabricated and experiments using $\mathrm{NaCl}$ aerosol particles as the condensation nucleus are conducted to verify the models. The isentropic model, suggests that the temperature drops $0.6^{\circ} \mathrm{C}$ within $40 \mathrm{~ms}$, and accordingly, the saturation ratio reaches 1.04. For an aerosol with lognormal distribution, the predicted geometric mean diameter grows more than 5 times while the distribution narrows due to $\propto 1 / d_{\mathrm{p}}$ growth in the continuum regime. The performance of the cloud chamber agrees with the system physics and reference instruments, with relative error in measured extinction coefficient and signal intensities of $\pm 5 \%$. Detailed error propagation shows that the measured number concentrations agree well with reference instruments and the underlying theory. The lower limit of detection $\left(\sim 4 \times 10^{6} \mathrm{~cm}^{-3}\right)$ for the device is suitable for fire detection and emissions characterization.
\end{abstract}

Keywords: cloud chamber, aerosol particles, adiabatic expansion, light extinction, particle detection

Conflict of interest: The authors declare that they have no conflict of interest. 


\section{Introduction}

Ultrafine particles transformed from indoor and outdoor air pollutions, consisting of particles with aerodynamic diameters smaller than $100 \mathrm{~nm}$, have enhanced health hazards over those attributed to $\mathrm{PM}_{2.5}$ owning to their relatively higher number concentration, specific surface areas, and potentials of deeper penetration into human lungs [1, 2]. However, an epidemiological research concerning on the health effect of airborne ultrafine particles is still limited due to a lack of low-cost instruments appropriate for monitoring local concentrations of ultrafine particles distributedly [3].

Cloud chambers are one type of fundamental devices used to investigate the formation and evolution of aerosol processes in recent years $[4,5]$. These devices were initially used to detect charged particles $[6,7]$ and subsequently extended to meteorological studies such as ice nucleation [8-10], atmospheric oxidation [11], and cloud microphysical processes [12]. Moreover, when combined with optical methods (light scatting or extinction), this technique can be applied to measure aerosol size distributions and concentrations [13-18]. Researchers have developed multiple cloud chamber designs [19-21], most of which employ adiabaticexpansion to condense a saturated fluid onto aerosol particles. In such chambers, vapor becomes supersaturated due to the adiabatic expansion of the gas and the working fluid condenses on aerosol particles. In most cases the Poisson equation provides an adequate approximation for the temperature after expansion when the speed of expansion is much slower than the velocity of sound [22-24]. However, this model overestimated the temperature changes associated with expansion if the expansion speed is comparable with sound speed due to the quasi-static assumption [24]. Moteki and Kondo [25] introduced a virtual path method to calculate the timedependent temperature and saturation ratio in an expansion chamber. This model is applicable to both slow and fast expansion speed for conventional expansion-type cloud chambers.

In order to achieve the desired vapor supersaturations, a traditional expansion chamber is usually connected with a low-pressure buffer tank. Adiabatic expansion is initiated by opening a valve located between the two vessels. Traditionally, the volume of the buffer tank is much larger than the volume of the chamber for conventional expansion-type chambers (volumetric ratio factor is up to 25) [24], therefore the thermodynamic state in the buffer tank remains practically unchanged when expansion occurs. As a result, previous models only consider the thermodynamic processes in the expansion chamber. However, if the difference in volume of the two vessels is not significant, e.g. in portable devices, the models that only consider the expansion chamber will not adequately predict the temperature change. The change of state in the buffer tank during the expansion process, such as pressure increase, will also influence the 
expansion speed and thereby affect the thermodynamic state in the expansion chamber. Under these conditions, one must consider the system consisting both of the cloud chamber and the buffer tank as one object to study the thermodynamic process.

In this paper, we evaluate the effectiveness of a low-cost cloud chamber for purposes of online ultrafine particle measurement using mathematically modelling method, which is widely used in the field of aerosol dynamics [26, 27]. To understand the operation of the device we derive a temporal discretization model describing the temperature, saturation ratio and particle growth in a cloud chamber used in compact devices assuming isentropic expansion in a quasistatic process. This model predicts the thermodynamic parameters of both the cloud chamber and the buffer tank with measured pressure values. This algorithm is applied to a multicomponent system accounting for the condensation of water vapor during the expansion process. As a comparison, another model based on isenthalpic expansion was also provided. Using a laboratory cloud chamber, the models were corrected in accordance to the measured values of temperature in the buffer tank and was verified by the temperature and light extinction in the cloud chamber. The symbols and subscripts of physical quantities used are summarized in Table 1 and Table 2 respectively.

\section{Methods}

Generally, the pressure in the buffer tank is much lower than that in an interconnected cloud chamber and the saturation ratio, $S_{\mathrm{R}}$, of water vapor in the cloud chamber is nearly $S_{\mathrm{R}} \sim 1$ at the beginning of expansion, such tha t upon expansion a supersaturated state can be easily achieved. In compact devices, the volume of the two vessels is usually several cubic centimeters and their volume ratio is typically, $1 \leq V_{\mathrm{B}} / V_{\mathrm{C}} \leq 10$. Figure 1 shows the schematic of the cloud chamber and corresponding components which were constructed of high-density plastic with integrated valves between the chambers. This device consists of a water chamber $\left(10 \mathrm{~cm}^{3}\right)$, cloud chamber $\left(3 \mathrm{~cm}^{3}\right)$, and a buffer tank $\left(30 \mathrm{~cm}^{3}\right)$. The water-containing chamber provides saturation vapor for the indrawn aerosol. Valves (A) between the chambers were used to control the temporal evolution of the process. Two electronic pressure (P) sensors (MPXV5050DP, Freescale) and two K-type thermocouples (Tc, SCASS-010G-6, Omega) are embedded within the buffer and the cloud chamber to monitor the relative pressure and temperature in both vessels. A micro diaphragm gas pump (NMP830KNDC, KNF) connects the outlet of the buffer tank to provide a low pressure region within the buffer tank. All the controlling signal and measured data were recorded through different channels of a data acquisition device (NI USB-6009). 


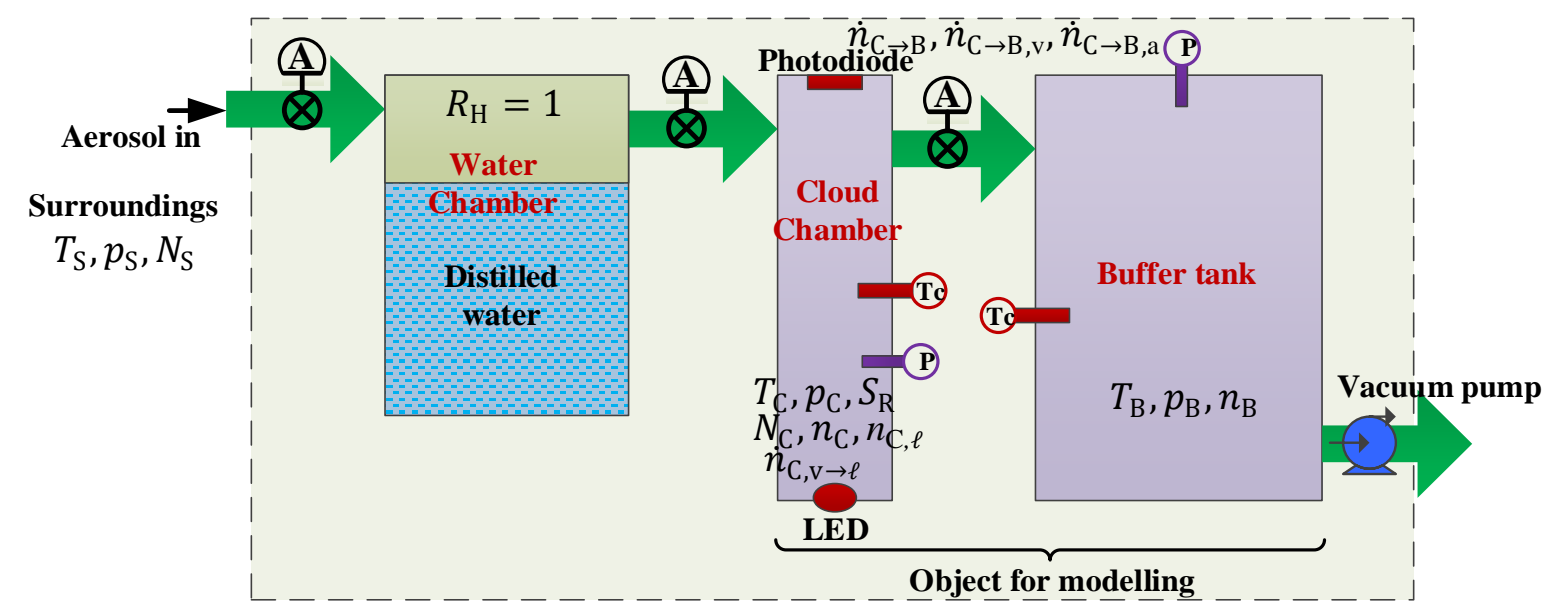

Fig. 1. Schematic diagram of the low-cost cloud chamber with comparable buffer tank and cloud chamber volumes. The actuators, pumps, pressure sensor, photodiode and LED are required for operation, whereas the thermocouples are used solely for experimental investigation.

Aerosols are sampled through a saturation chamber into the cloud chamber before expansion occurs. The effects of thermal conduction from surroundings, the gravitational settling of droplets and the diffusional loss of aerosol particles in the cloud chamber are negligible owning to the short expansion time.

The model used to describe the cloud chamber operation and particle detection is shown in Fig. 2, which is primarily composed of a thermodynamic model used to determine temperature changes, vapor pressures, particle growth, species transport and conservation equations. Isentropic and isenthalpic principles are compared to determine the behaviour that fits the measured system dynamics. A light scattering model is also incorporated to allow comparison to scanning mobility particle sizer (SMPS) results, which is composed of Bouguer's Law, extinction coefficient and particle concentration calculations. The model approach is shown in Fig. A1 in the Appendix and described further in the following sections. In Fig. 2, FM and CR represent free molecule and continuum regime, respectively. 


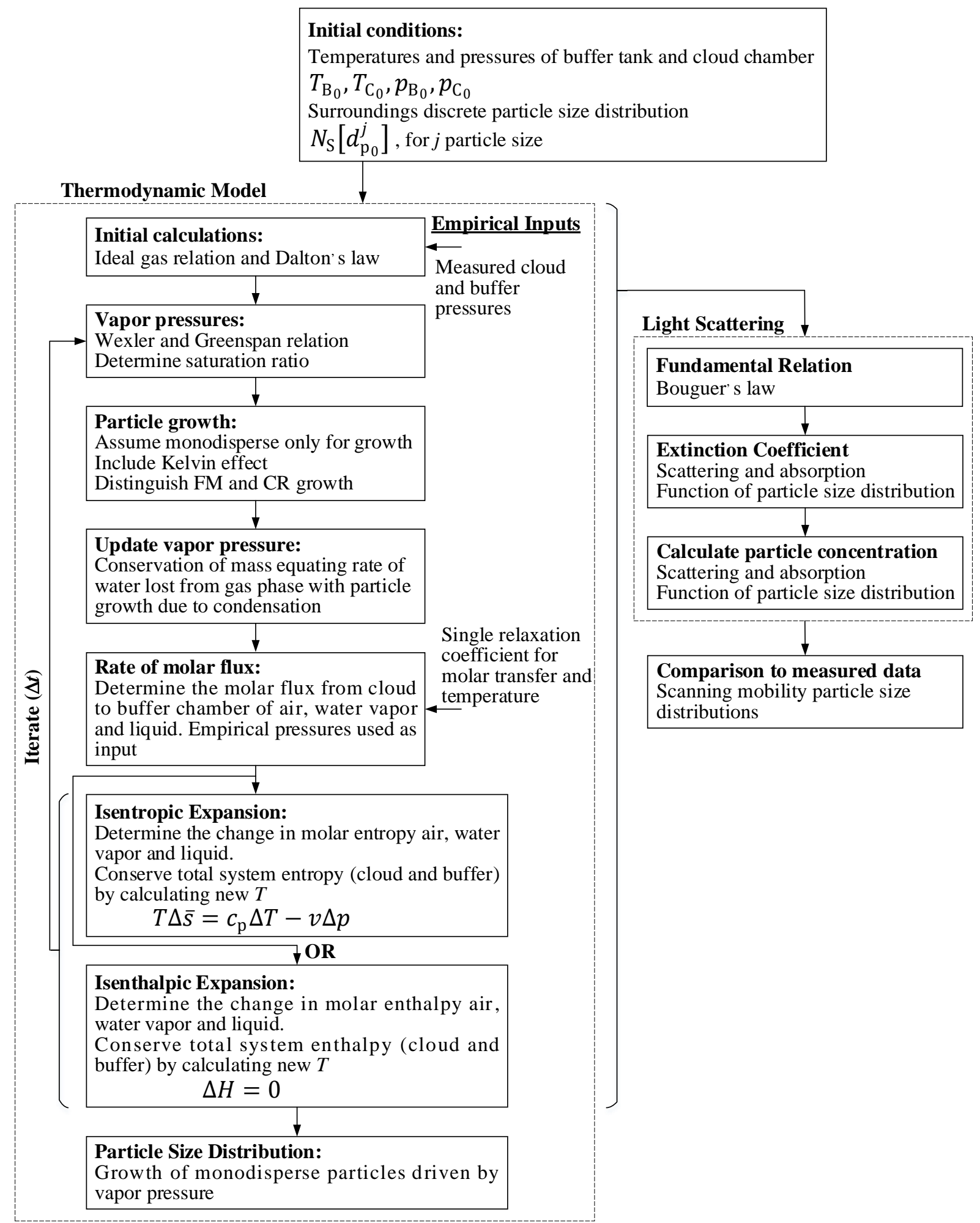

Fig. 2. Model approach for determination of particle growth in a cloud chamber with comparable buffer tank and cloud chamber volumes, comprising of a thermodynamic algorithm and light scattering algorithm in separate subroutines. Further detail is given in the Appendix.

\subsection{Vapor pressures}

The initial calculations solve for the molar concentrations of water vapor and air molecules based on the ideal gas law and Dalton's law of partial pressures. It is assumed that the ratio of 
the total number of particles to dry air molecules within the cloud chamber is constant in time subsequent to their entry to the cloud chamber. This ratio can be expressed as

$$
\widehat{N}=\frac{N_{\mathrm{num}_{0}}}{n_{\mathrm{C}, \mathrm{a}_{0}}}=\frac{p_{\mathrm{C}_{0} V_{\mathrm{C}} T_{\mathrm{S}} N_{\mathrm{S}}}}{n_{\mathrm{C}, \mathrm{a}_{0} T_{\mathrm{C}_{0}} p_{\mathrm{S}}}}
$$

where $N_{\mathrm{S}}$ is the number concentration of aerosol particles in the surrounding environment which is also denoted by the subscript $\mathrm{S}$ for other parameters. We use Wexler and Greenspan's expression [28] to compute the saturation vapor pressure at time $i$ in the cloud chamber.

$p_{\text {sat }_{i}}=\exp \left[\begin{array}{c}-0.3 \times 10^{4}\left(T_{\mathrm{C}_{i}}\right)^{-2}-0.60 \times 10^{4}\left(T_{\mathrm{C}_{i}}\right)^{-1}+18.88-0.28 \times 10^{-1} T_{\mathrm{C}_{i}}+ \\ 0.18 \times 10^{-4}\left(T_{\mathrm{C}_{i}}\right)^{2}-0.84 \times 10^{-9}\left(T_{\mathrm{C}_{i}}\right)^{3}+0.44 \times 10^{-12}\left(T_{\mathrm{C}_{i}}\right)^{4}+2.86 \ln \left(T_{\mathrm{C}_{i}}\right)\end{array}\right]$

\subsection{Vapor Condensation}

The rate of water vapor condensing during expansion was calculated during the period $\Delta t$. For simplicity, monodisperse aerosol particles are assumed solely for the purpose of determining the flux of condensing water, while polydisperse particle growth is solved explicitly. Particle growth was determined using discrete timesteps for particles in the free molecular regime (particle diameter $d_{\mathrm{p}_{i}}<$ mean free path $\lambda_{i}$ ) [29]

$$
\Delta d_{\mathrm{p}_{i}}=\frac{2 V_{\mathrm{m}} \alpha_{\mathrm{c}}}{\left(2 \pi m k_{\mathrm{B}} T_{C_{i}}\right)^{1 / 2}}\left(p_{\mathrm{C}, \mathrm{v}_{i}}-p_{\mathrm{d}_{i}}\right) \cdot \Delta t
$$

or for the continuum regime,

$$
\Delta d_{\mathrm{p}_{i}}=\frac{4 D_{\mathrm{v}} V_{\mathrm{m}} N_{\mathrm{A}}}{R d_{\mathrm{p}_{i}}}\left(\frac{p_{\mathrm{C}, \mathrm{v}_{i}}}{T_{\mathrm{C}_{i}}}-\frac{p_{\mathrm{d}_{i}}}{T_{\mathrm{d}_{i}}}\right) \cdot \phi_{i} \cdot \Delta t
$$

where $p_{d_{i}}$ is the partial pressure of water vapor at the particle surface, $V_{\mathrm{m}}$ is the volume of a water molecule, $\alpha_{\mathrm{c}}$ is the condensation coefficient, $m$ is the mass of water molecules, $k_{\mathrm{B}}$ is Boltzmann constant, $N_{\mathrm{A}}$ is the Avogadro constant, $D_{\mathrm{v}}$ is the diffusion coefficient of water vapor in air. The vapor pressure at the particle surface for high curvatures was accounted for by the Kelvin relation and the Fuchs correction factor $\phi_{i}$ is used to modify the growth in the continuum regime [30]. The temperature at the particle surface is determined using the empirical relation [29]

$$
T_{\mathrm{d}_{i}}=T_{\mathrm{C}_{i}}+\frac{\left(6.65+0.345 T_{\mathrm{C}_{i}}+0.0031 T_{\mathrm{C}_{i}}{ }^{2}\right)\left(S_{\mathrm{R}_{i}}-1\right)}{1+\left(0.082+0.00782 T_{\mathrm{C}_{i}}\right) S_{\mathrm{R}_{i}}}
$$

where $S_{\mathrm{R}_{i}}=p_{\mathrm{C}, \mathrm{v}_{i}} / p_{\mathrm{sat}_{i}}$ is the saturation ratio. Then the particle diameter at time $i+1$ is found in discrete increments for a monodisperse distribution $\left(d_{\mathrm{p}_{i+1}}=d_{\mathrm{p}_{i}}+\Delta d_{\mathrm{p}_{i}}\right)$ and the molecular flux of water vapor condensing onto particles during the period from $i$ to $i+1$ is 


$$
\dot{n}_{\mathrm{C}, \mathrm{v} \rightarrow \ell_{i}}=\frac{\pi\left(\left(d_{\mathrm{p}_{i}}+\Delta d_{\mathrm{p}_{i}}\right)^{3}-\left(d_{\mathrm{p}_{i}}\right)^{3}\right) \widehat{N} n_{\mathrm{C}, \mathrm{a}_{i}}}{6 V_{\mathrm{m}} N_{\mathrm{A}}}
$$

These quantities allow for temperature to be determined by of isentropic assumption, as shown below. Accordingly, we obtain the particle growth and the saturation ratio in the cloud chamber.

\subsection{Growth of polydisperse particles}

The particle growth in Eqn. (3) is diameter related. For polydisperse aerosol with size distribution $N\left[d_{\mathrm{p}}\right]$, the growth for each size interval is $\Delta d_{\mathrm{p}_{i}}^{j}$, where $j$ represents the $j^{\text {th }}$ size interval. Then the particle diameter after growth is $d_{\mathrm{p}_{i+1}}^{j}=d_{\mathrm{p}_{i}}^{j}+\Delta d_{\mathrm{p}_{i}}^{j}$ and the amount of water vapor condensed on the entire polydisperse aerosol is

$$
\dot{n}_{\mathrm{C}, \mathrm{v} \rightarrow \ell_{i}}=\frac{\pi n_{\mathrm{C}, \mathrm{a}_{i}}}{6 V_{\mathrm{m}} N_{A}} \sum_{d_{\mathrm{p}_{i}}^{j}=d_{\mathrm{p}, \min }}^{d_{\mathrm{p} \text { max }}}\left[\left(d_{\mathrm{p}_{i}}^{j}+\Delta d_{\mathrm{p}_{i}}^{j}\right)^{3}-\left(d_{\mathrm{p}_{i}}^{j}\right)^{3}\right] \widehat{N}^{j}
$$

where

$$
\widehat{N}^{j}=\frac{p_{\mathrm{C}_{0} V_{\mathrm{C}} T_{\mathrm{S}} N_{\mathrm{S}}}\left[d_{\mathrm{p}_{0}}^{j}\right]}{n_{\mathrm{C}, \mathrm{a}_{0} T_{\mathrm{C}_{0}}} p_{\mathrm{S}}}
$$

The number of particles in the $j^{\text {th }}$ size interval after condensation is $N_{\text {num }_{i}}^{j}=\widehat{N}^{j} n_{\mathrm{C}, \mathrm{a}_{i}}$ and accordingly, the number concentration in the $j^{\text {th }}$ size interval is $N_{\mathrm{C}_{i}}^{j}=N_{\text {num }}^{j} / V_{\mathrm{C}}$. The size distribution of the aerosol after condensation was determined using $d_{\mathrm{p}_{i}}^{j}$ and $N_{\mathrm{C}_{i}}^{j}$.

\subsection{Time evolution of temperature}

\subsubsection{Method based on isentropic expansion}

By assuming a quasi-static isentropic expansion process, the governing relationship for temperature $T$ at a given time point $i$ can be determined for the cloud chamber and buffer tank. It is assumed that the total entropy of the combine system comprised of dry air, water vapor and liquid water in the two vessels is invariant during the expansion. At time $i$, the isentropic process for the system may be expressed as

$S_{i}=\overbrace{n_{\mathrm{B}, \mathrm{v}_{i}} \bar{s}_{\mathrm{B}, \mathrm{v}_{i}}\left(T_{\mathrm{B}_{i}}\right)}^{S_{B, v_{i}}}+\overbrace{n_{\mathrm{B}, \mathrm{a}_{i}} \bar{s}_{\mathrm{B}, \mathrm{a}_{i}}\left(T_{\mathrm{B}_{i}}\right)}^{\begin{array}{c}\text { Buffer vapor } \\ S_{B, a_{i}}\end{array}}+\overbrace{n_{\mathrm{C}, \mathrm{v}_{i}} \bar{s}_{\mathrm{C}, \mathrm{v}_{i}}\left(T_{\mathrm{C}_{i}}\right)}^{s_{C, v_{i}}}+\overbrace{n_{\mathrm{C}, \mathrm{a}_{i}} \bar{s}_{\mathrm{C}, \mathrm{a}_{i}}\left(T_{\mathrm{C}_{i}}\right)}^{\begin{array}{c}\text { Cloud vapor } \\ S_{\mathrm{C}, a_{i}}\end{array}}+\overbrace{n_{\mathrm{C}, \ell_{i}} \bar{s}_{\mathrm{C}, \ell_{i}}\left(T_{\mathrm{C}_{i}}\right)}^{\begin{array}{c}\text { Cloud liquid } \\ S_{\mathrm{C}, \ell_{i}}\end{array}}$

where $n[\mathrm{~mol}]$ and $\bar{s}[$ e.g. J/K·mol] are amount of substance and specific entropy, respectively. The capitalized subscripts indicate the location of the species within the buffer tank (B) or cloud chamber (C) and lower case scripts indicate the species, such as water vapor (v), dry air (a) and liquid water $(\ell)$. Similarly, the total entropy at the time point of $i+1$ is determined by accounting for the molar flux of species changing location and state, e.g. $s_{B, v_{i+1}}=\left(n_{\mathrm{B}, \mathrm{v}_{i}}+\right.$ 
$\left.\dot{n}_{\mathrm{C} \rightarrow \mathrm{B}, \mathrm{v}_{i}}\right) \bar{s}_{\mathrm{B}, \mathrm{v}_{i+1}}\left(T_{\mathrm{B}_{i+1}}\right)$, where $\dot{n}_{\mathrm{C} \rightarrow \mathrm{B}}$ is the flux of substance entering the buffer tank from the cloud chamber. Assuming a quasi-static processes, the total entropy of the substances in two vessels does not change, specifically $S_{i+1}=S_{i}$. Using the thermodynamic formulation for a quasi-static process, $T \Delta \bar{s}=c_{\mathrm{p}} \Delta T-v \Delta p$ and the equation of state for an ideal gas composed of air and water vapor, $p V=n R T$, an approximation of the change in entropy is found,

$$
\Delta \bar{S}=c_{\mathrm{p}} \ln \frac{T_{i+1}}{T_{i}}-R \ln \frac{p_{i+1}}{p_{i}} \approx c_{\mathrm{p}} \frac{T_{i+1}-T_{i}}{T_{i}}-R \frac{p_{i+1}-p_{i}}{p_{i}}
$$

for two states of $i$ and $i+1$ between which the thermodynamic parameters charge very little, where $c_{\mathrm{p}}$ is the specific heat at constant pressure, $R$ is the general ideal gas constant, $v$ is the specific volume, and $p$ is pressure. To calculate the temperature $T_{\mathrm{C}_{i+1}}$, the incremental pressures and molar concentrations are solved from the ideal gas state equations and conservation of mass equations for each incremental timestep, as shown in the Appendix. The resulting incremental molar and temperature values are reduced to the following form,

$$
\begin{gathered}
\dot{n}_{\mathrm{C} \rightarrow \mathrm{B}_{i}}=n_{\mathrm{C}_{i}}\left(1-\frac{b_{i}}{n_{\mathrm{C}_{i}} T_{\mathrm{C}_{i+1}}}-\frac{\dot{n}_{\mathrm{C}, \mathrm{v} \rightarrow \ell_{i}}}{n_{\mathrm{C}_{i}}}\right) \\
\dot{n}_{\mathrm{C} \rightarrow \mathrm{B}, \mathrm{v}_{i}}=n_{\mathrm{C}, \mathrm{v}_{i}}\left(1-\frac{b_{i}}{n_{\mathrm{C}_{i}} T_{\mathrm{C}_{i+1}}}-\frac{\dot{n}_{\mathrm{C}, \mathrm{v} \rightarrow \ell_{i}}}{n_{\mathrm{C}_{i}}}\right) \\
\dot{n}_{\mathrm{C} \rightarrow \mathrm{B}, \mathrm{a}_{i}}=n_{\mathrm{C}, \mathrm{a}_{i}}\left(1-\frac{b_{i}}{n_{\mathrm{C}_{i}} T_{\mathrm{C}_{i+1}}}-\frac{\dot{n}_{\mathrm{C}, \mathrm{v} \rightarrow \ell_{i}}}{n_{\mathrm{C}_{i}}}\right) \\
T_{\mathrm{B}_{i+1}}=\frac{p_{\mathrm{B}_{i+1}} V_{\mathrm{B}} T_{\mathrm{C}_{i+1}}}{r_{i} T_{\mathrm{C}_{i+1}}-p_{\mathrm{C}_{i+1}} V_{\mathrm{C}}}
\end{gathered}
$$

where $b_{i}=p_{\mathrm{C}_{i+1}} V_{\mathrm{C}} / R$, and $r_{i}=R\left(n_{\mathrm{C}_{i}}+n_{\mathrm{B}_{i}}-\dot{n}_{\mathrm{C}, \mathrm{v} \rightarrow \ell_{i}}\right)$. The following equation describing the temperature evolution in the cloud chamber is a fifth order polynomial

$$
C_{i}^{1} T_{\mathrm{C}_{i+1}}{ }^{5}+C_{i}^{2} T_{\mathrm{C}_{i+1}}{ }^{4}+C_{i}^{3} T_{\mathrm{C}_{i+1}}{ }^{3}+C_{i}^{4} T_{\mathrm{C}_{i+1}}{ }^{2}+C_{i}^{5} T_{\mathrm{C}_{i+1}}+C_{i}^{6}=0,
$$

where the coefficients $C_{i}^{1}-C_{i}^{6}$ are combinations of variables at time $i$ (obtained from initial conditions or the calculation of previous step), pressures (measured experimentally) and other known parameters, except for the condensation flux $\dot{n}_{\mathrm{C}, \mathrm{v} \rightarrow \ell_{i}}$ which is calculated from Eqns. (5) or (6). A detailed derivation of Eqn. (11) is given in the Appendix. Coefficients defined during the derivation of equations (11) are given in Table 3.

\subsubsection{Method based on isenthalpic expansion}

An equation describing time evolution based on isenthalpic expansion for the system composed of the two vessels was also derived. Assuming total energy is constant during the expansion (isenthalpic), the following relation represents the isenthalpic changes during the expansion at times $i$ and $i+1$. 


$$
\begin{aligned}
& \Delta H=\overbrace{n_{\mathrm{B}, \mathrm{v}_{i}} c_{\mathrm{p}, \mathrm{v}}\left(T_{\mathrm{B}_{i+1}}-T_{\mathrm{B}_{i}}\right)}^{\Delta h_{B, v}}+\overbrace{n_{\mathrm{B}, \mathrm{a}_{i}} c_{\mathrm{p}, \mathrm{a}}\left(T_{\mathrm{B}_{i+1}}-T_{\mathrm{B}_{i}}\right)}^{\begin{array}{c}
\text { Buffer vapor } \\
\Delta h_{B, v}
\end{array}}+\overbrace{n_{\mathrm{C}, \mathrm{v}_{i}} c_{\mathrm{p}, \mathrm{v}}\left(T_{C_{i+1}}-T_{\mathrm{C}_{i}}\right)}^{\Delta h_{C, v}}+ \\
& \overbrace{n_{\mathrm{C}, \mathrm{a}_{i}} c_{\mathrm{p}, \mathrm{a}}\left(T_{\mathrm{C}_{i+1}}-T_{\mathrm{C}_{i}}\right)}^{\Delta h_{\mathrm{C}, a}}+\overbrace{n_{\mathrm{C}, \ell_{i}} c_{\mathrm{p}, \ell}\left(T_{\mathrm{C}_{i+1}}-T_{\mathrm{C}_{i}}\right)}^{\Delta h_{\mathrm{C}, \ell}}+\overbrace{\dot{n}_{\mathrm{C} \rightarrow \mathrm{B}, \mathrm{v}_{i}} c_{\mathrm{p}, \mathrm{v}}\left(T_{\mathrm{B}_{i+1}}-T_{\mathrm{C}_{i+1}}\right)}^{\begin{array}{c}
\text { Cloud liquid } \\
\Delta h_{\mathrm{C} \rightarrow \mathrm{B}, \mathrm{v}}
\end{array}}+ \\
& \overbrace{\dot{n}_{\mathrm{C} \rightarrow \mathrm{B}, \mathrm{a}_{i}} c_{\mathrm{p}, \mathrm{a}}\left(T_{\mathrm{B}_{i+1}}-T_{\mathrm{C}_{i+1}}\right)}^{\begin{array}{c}
\text { Cloud to Buffer air } \\
\Delta h_{\mathrm{C} \rightarrow \mathrm{B}, \mathrm{a}}
\end{array}}+\overbrace{\dot{n}_{\mathrm{C}, \mathrm{v} \rightarrow \ell_{i}} L}^{\Delta h_{\mathrm{v} \rightarrow \ell}}=0
\end{aligned}
$$

After rearrangement and substitution of Eqns. (10a-d), we obtained the following quadratic polynomial equation,

$$
C_{i}^{7} T_{\mathrm{C}_{i+1}}{ }^{2}+C_{i}^{8} T_{\mathrm{C}_{i+1}}+C_{i}^{9}=0,
$$

where $C_{i}^{7}-C_{i}^{9}$ are variables composed of comparable thermodynamic and system parameters similar to Eqn. (11). Further details are provided in the Appendix. Coefficients defined during the derivation of equations (13) are also given in Table 3. Compared with the result based on isentropic expansion, this numerical solution for equation is relatively less computationally expensive but less accurate as shown below.

\subsection{Model correction}

Direct solutions of Eqns. (11) and (13) using initial conditions and pressure values of the expansion process were larger than reasonable due to quasi-static assumption and the calculation errors. Large variations in the resultant temperature between time evolution points result in large changes in the coefficients of equation, which caused further numerical inaccuracies. To stabilize the evolutive solution process and slow the changes in results between evolutions, an under-relaxation technique was adopted as shown previously effective [31]. The change of temperature in both vessels and the amounts of substance flowing from the cloud chamber to the buffer tank can be modified by the introduction of a relaxation factor $\eta$, such that

$$
\begin{gathered}
T_{\mathrm{C}_{i+1}}=T_{\mathrm{C}_{i}}+\eta\left(T_{\mathrm{C}_{i+1}}^{*}-T_{\mathrm{C}_{i}}\right) \\
T_{\mathrm{B}_{i+1}}=T_{\mathrm{B}_{i}}+\eta\left(T_{\mathrm{B}_{i+1}}^{*}-T_{\mathrm{B}_{i}}\right) \\
\dot{n}_{{\mathrm{C} \rightarrow \mathrm{B}_{i}}}=\eta \dot{n}_{\mathrm{C} \rightarrow \mathrm{B}_{i}}^{*}
\end{gathered}
$$

where $T_{\mathrm{C}_{i+1}}^{*}, T_{\mathrm{B}_{i+1}}^{*}$, and $\dot{n}_{\mathrm{C} \rightarrow \mathrm{B}_{i}}^{*}$ represent the values from the previous evolution step. The factors affecting $\eta$ values include the size of time interval $\Delta t$, the difference of pressure and the structure of channel between the two vessels. The exact value of $\eta$ is determined by preliminary calculations of $T_{\mathrm{C}_{i+1}}$ and a comparison with experimental results in our study. The resultant temperature change in time is then iterated through subsequent loops as shown in Fig. 2. 


\subsection{Light extinction in cloud chamber}

According to Bouguer's Law, the ratio of the light intensity traversing an aerosol to that incident on the aerosol is

$$
\frac{I}{I_{0}}=e^{-L_{\mathrm{b}} \sigma_{\mathrm{e}}}
$$

where $L_{\mathrm{b}}$ is the path length of the light beam through the aerosol, $\sigma_{\mathrm{e}}$ is the extinction coefficient. For polydisperse aerosol, the overall extinction coefficient can be expressed as

$$
\sigma_{\mathrm{e}}=\int_{d_{\mathrm{p}, \min }}^{d_{\mathrm{p}, \max }} \frac{\pi\left(d_{\mathrm{p}}\right)^{2}}{4} Q_{\mathrm{e}} N_{\mathrm{C}_{f}}\left[d_{\mathrm{p}}\right] \mathrm{d}\left(d_{\mathrm{p}}\right)
$$

where $N_{\mathrm{C}_{f}}\left[d_{\mathrm{p}}\right]$ is the size distribution function (concentration per size) after condensation in the cloud chamber, $Q_{\mathrm{e}}$ is the extinction efficiency which depends on the particle refractive index, shape and size relative to the wavelength of light.

The extinction coefficient $\sigma_{\mathrm{e}}$ can be obtained by combining the effects of scattering with absorption. Here we use harmonic mean type approximation and method of moment to estimate $\sigma_{\mathrm{e}}$. Following these methods, the approximated overall extinction coefficient can be expressed as a moment function [32]

$$
\sigma_{\mathrm{e}}=\frac{\left(\xi_{1} M_{3}+\xi_{2} M_{6}\right)\left(\varsigma_{1} M_{2}+\varsigma_{2} M_{4 / 3}\right)}{\xi_{1} M_{3}+\xi_{2} M_{6}+\varsigma_{1} M_{2}+\varsigma_{2} M_{4 / 3}}
$$

here,

$$
\xi_{1}=\frac{\pi^{2}}{\lambda_{\mathrm{L}}} \operatorname{Im}\left[\frac{m_{\mathrm{r}}^{2}-1}{m_{\mathrm{r}}^{2}+2}\right], \xi_{2}=\frac{2 \pi}{3}\left(\frac{\pi}{\lambda_{\mathrm{L}}}\right)^{4} \operatorname{Re}\left[\left(\frac{m_{\mathrm{r}}^{2}-1}{m_{\mathrm{r}}^{2}+2}\right)^{2}\right], \quad \varsigma_{1}=\frac{\pi}{2}, \quad \varsigma_{2}=\frac{\pi}{2}\left(\frac{\pi}{\lambda_{\mathrm{L}}}\right)^{-2 / 3}
$$

$\lambda_{\mathrm{L}}$ is the wavelength of the incident light, $m_{\mathrm{r}}$ is the complex refractive index of the particles. The $k^{\text {th }}$ moment is

$$
M_{k}=\int_{0}^{\infty}\left(d_{\mathrm{p}}\right)^{k} N_{\mathrm{C}_{f}}\left[d_{\mathrm{p}}\right] \mathrm{d}\left(d_{\mathrm{p}}\right) \approx \sum_{d_{\mathrm{p}}^{j}=d_{\mathrm{p}, \min }}^{d_{\mathrm{p} \max }}\left(d_{\mathrm{p}}^{j}\right)^{k} N_{\mathrm{C}_{f}}\left[d_{\mathrm{p}}\right] .
$$

The moment of a log-normal distribution is related to the geometric mean and standard deviation by $M_{k}=\left(\bar{d}_{\mathrm{pg}}\right)^{k} e^{k^{2} \ln \left[\sigma_{\mathrm{g}}\right]^{2}}$, where $\bar{d}_{\mathrm{pg}}$ and $\sigma_{\mathrm{g}}$ are the geometric mean diameter and standard deviation, respectively. For a $m_{\mathrm{r}}=1.3310+2.2851 \times 10^{-8} \mathrm{i}$ and $\lambda_{\mathrm{L}}=680 \mathrm{~nm}$, the

$$
\sigma_{\mathrm{e}} \approx C_{1} N_{\mathrm{C}_{f}}\left(\bar{d}_{\mathrm{pg}}\right)^{x}
$$

over the range of $\bar{d}_{\mathrm{pg}}=[50-500 \mathrm{~nm}]$ and $\sigma_{\mathrm{g}}=[1.2-1.5]$ explored herein. $C_{1}$ and $x$ are the coefficient to be determined. The geometric mean diameter $\bar{d}_{\mathrm{pg}}$ and standard deviation $\sigma_{\mathrm{g}}$ of the aerosol size distribution after condensation are calculated accordingly (see Appendix). These results are compared to experimentally measured values using a separate SMPS system. 


\subsection{Experimental method}

The frame of the laboratory cloud chamber is gotten from Protec Company, UK. The light extinction due to cloud formation in the cloud chamber was measured throughout the experiments, while parallel measurements of size distributions were conducted with an SMPS (TSI 3938). Another CPC in parallel with the SMPS is used to monitor the total number concentrations as a reference. Dilution with ratio of up to 100 is needed in this branch. The corresponding set-up is shown in Fig. 3. Nearly lognormal dry $\mathrm{NaCl}$ aerosols with the mean diameter of $80-120 \mathrm{~nm}$ were generated by an atomizer and a diffusion dryer. Desired number concentrations $\left(3.3 \times 10^{5}-4.1 \times 10^{7} \mathrm{~cm}^{-3}\right)$ were obtained by defined flow rates of pure dilution gas, and the size distribution was used to calculate the corresponding extinction coefficients. The changes in photocurrent resultant from the cloud formation were continuously monitored as recorded voltage.

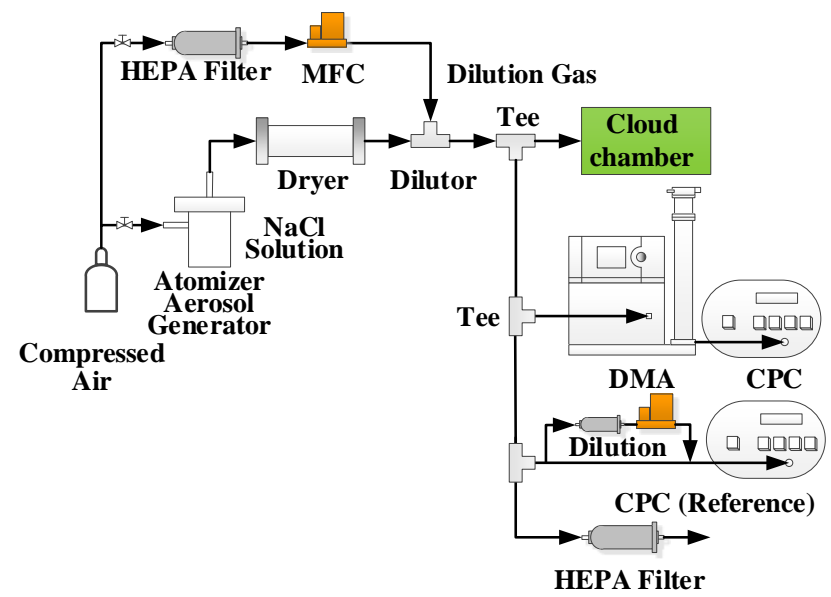

Fig. 3. Experimental set-up for testing the light extinction in the cloud chamber consisting of a atomized $\mathrm{NaCl}$ solution that is dried then diluted before passing to parallel measurements using an SMPS and cloud chamber.

\section{Results}

\subsection{Temporal response of the cloud chamber}

The pressure, temperature and photodiode signals are monitored throughout the expansion process, with the results of the expansions shown Fig. 4. At the beginning of the expansion, the pressure in the buffer tank is nearly one half of that in the cloud chamber. During $40 \mathrm{~ms}$ after the valve opens, air expands from the cloud chamber into the buffer tank and pressure in the cloud chamber decreases rapidly. The temperature reduces as a result of the expansion process, which raises the saturation ratio and induces condensation. A minimum of light signal is detected at the end of the expansion due to the increased attenuation of light caused by the larger droplets. 
$\mathrm{NaCl}$ particles generated by atomization served as the testing aerosol. However, there is almost no difference of the pressure in the two chambers when different types of aerosol and their size distribution were used (results not shown as they are identical within the limits of detection). The temperature in the device changes with that of the surroundings, but the relative change of it during expansion is nearly constant.

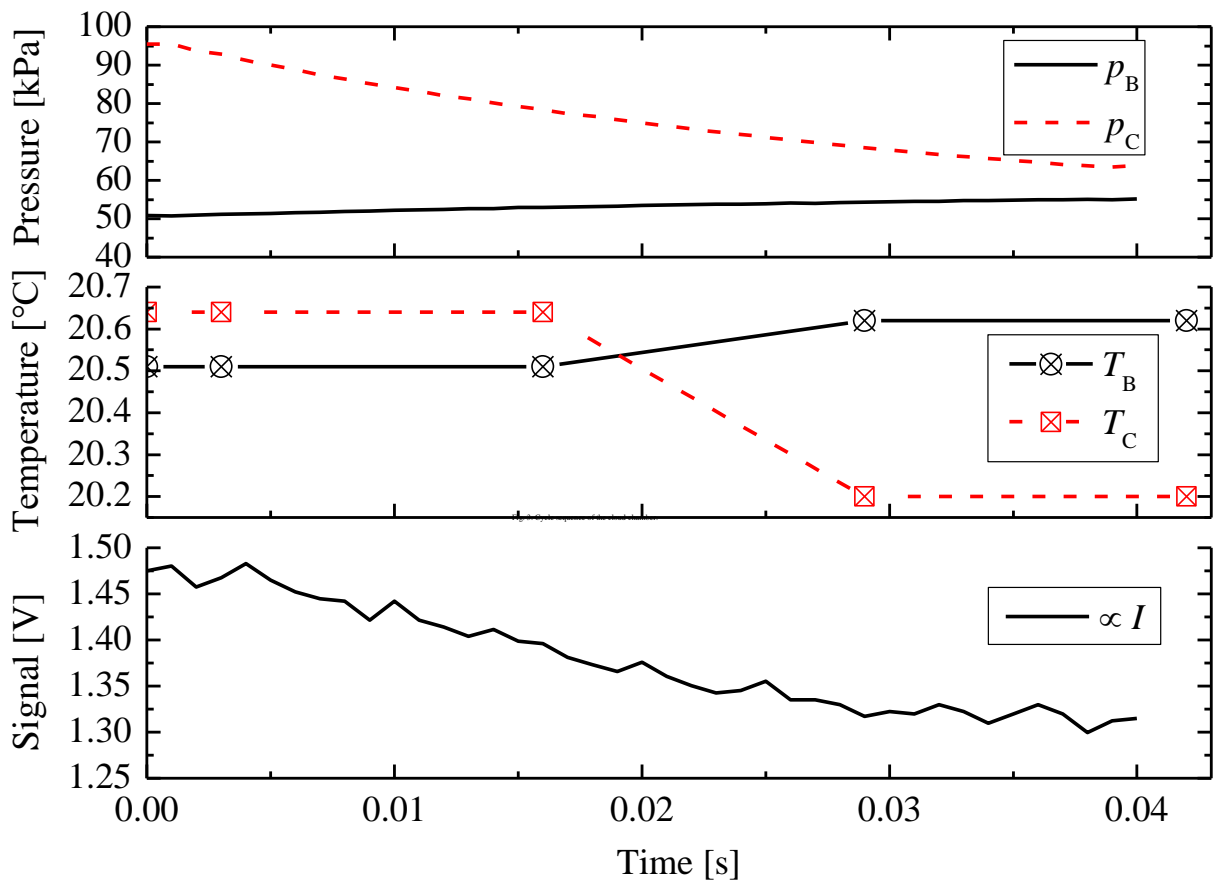

Fig. 4. The measured pressure (top), temperature (middle) and photo signal (bottom) in the buffer tank (B, black) and cloud chamber $(\mathrm{C}$, red) during after the expansion process is initiated.

The thermodynamic model of the cloud chamber is compared between two bounding cases, isentropic and isenthalpic expansion. The models depicted in Fig. 5, represent the expansion process in the cloud chamber where shear $\tau_{w}$ at the reactor walls is either negligible $(\Delta S=0)$ or significant $(\Delta H=0)$. Both models are initiated with ambient conditions to solve the temporal discretization model. These variables include the particle size distribution and ambient humidity levels. For the cloud chamber used in our experiments, the value of $\eta=0.0023$ is determined for the for isentropic expansion and as $\eta=0.023$ for isenthalpic expansion based on preliminary calculations when $\Delta t=0.005 \mathrm{~s}$. Fig. 5 shows the temperature evolution in the cloud chamber and the buffer tank during adiabatic expansion when a monodisperse aerosol was modelled $\left(d_{\mathrm{p}}=80 \mathrm{~nm}, N=10^{6} \mathrm{~cm}^{-3}\right)$ for the two methods. Temperature measurement frequency within the chambers is limited by the thermal mass of the thermocouple, limiting our measurement time resolution to $13 \mathrm{~ms}$. The measured temperature values over the $40 \mathrm{~ms}$ expansion show good agreement with that predicted by the corrected models (with a mean relative error less than $0.12 \%$ ) for the temperature in the buffer tank. The temperature decrease in the cloud chamber is vastly overestimated by the method based on isenthalpic expansion, 
while that predicted by the isentropic method is reasonable. Therefore, the system is presumed to have low non-conservative losses within the cloud chamber during the expansion, which may in part be due to the high aspect ratio of the device (4:1 width:depth) such that shear at the wall is negligible. As the modelled and measured temperature in the buffer tank increases, there is a concurrent decrease in temperature within the cloud chamber.
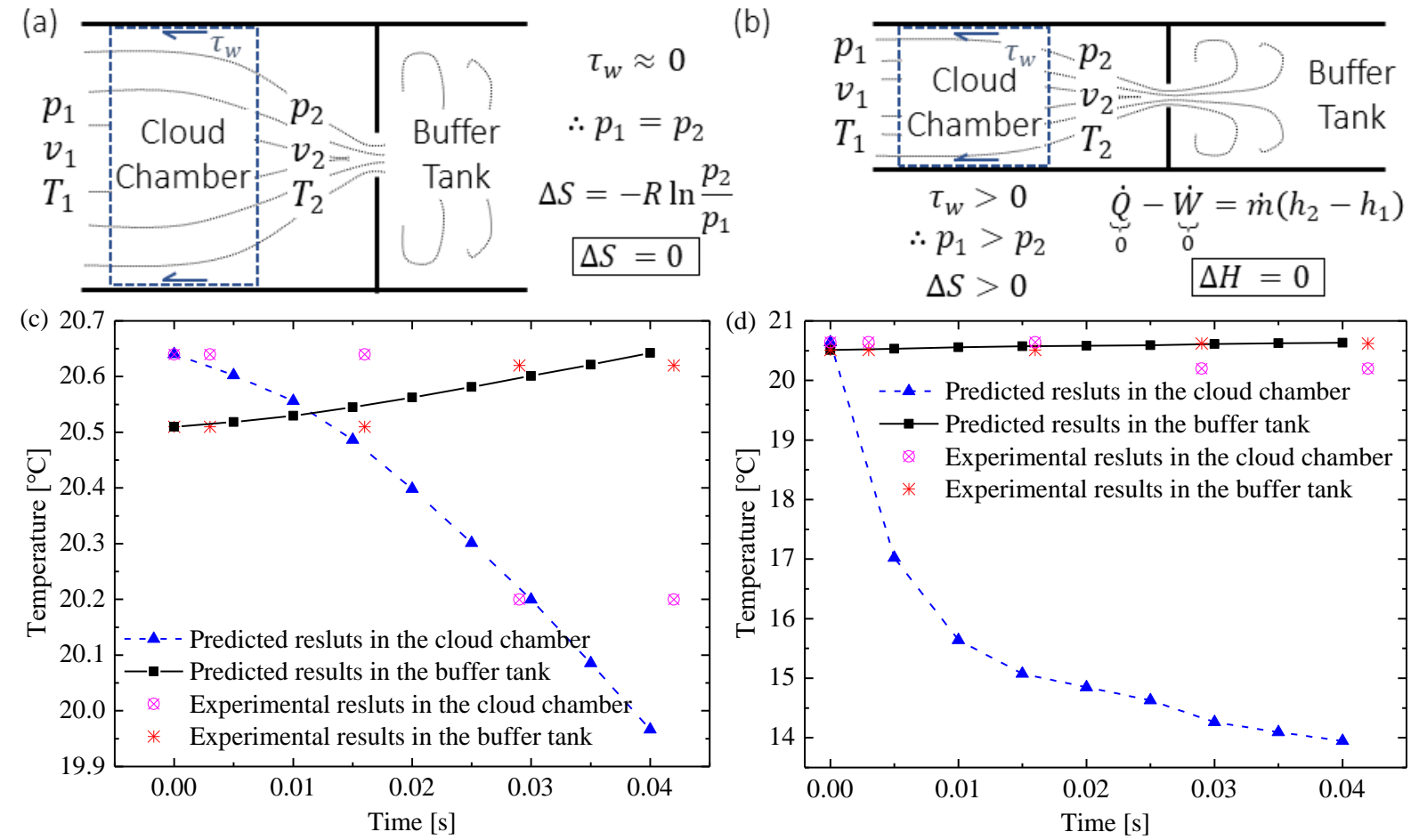

Fig. 5. Theoretical models governing the evolution of temperature for (a) isentropic and (b) isenthalpic expansion in the cloud chamber. Experimentally measured and modelled in the buffer tank and the cloud chamber during adiabatic expansion (monodisperse aerosol, $d_{\mathrm{p}}=80 \mathrm{~nm}, N=10^{6} \mathrm{~cm}^{-3}$ ) with predicted results (c) based on isentropic and (d) based on isenthalpic expansion.

The results predicted by the isentropic model show that the temperature in the cloud chamber drops $0.58{ }^{\circ} \mathrm{C}$ during the adiabatic expansion. The resulting saturation ration, shown in Fig. 6a, indicates that the initially saturated aerosol $\left(S_{\mathrm{R}_{0}}=1\right)$ begins to supersaturate as the temperature drops, providing a driving potential for condensation. The concurrent rise in saturation ratio and condensation does not reach an equilibrium state within the short timeframe of the expansion. The peak saturation ratio $\left(S_{\mathrm{R}_{0}}=1.04\right)$ is achieved at the end of the expansion process. The resulting modelled particle growth of the monodisperse system achieves 3-fold increase in diameter of particles with an initial diameter of $d_{\mathrm{p}}=80 \mathrm{~nm}$ owning to condensation. Other monodisperse distributions had similar modelled growths with larger particles having lower overall growth, as that shown in Fig. A2 in the Appendix. 

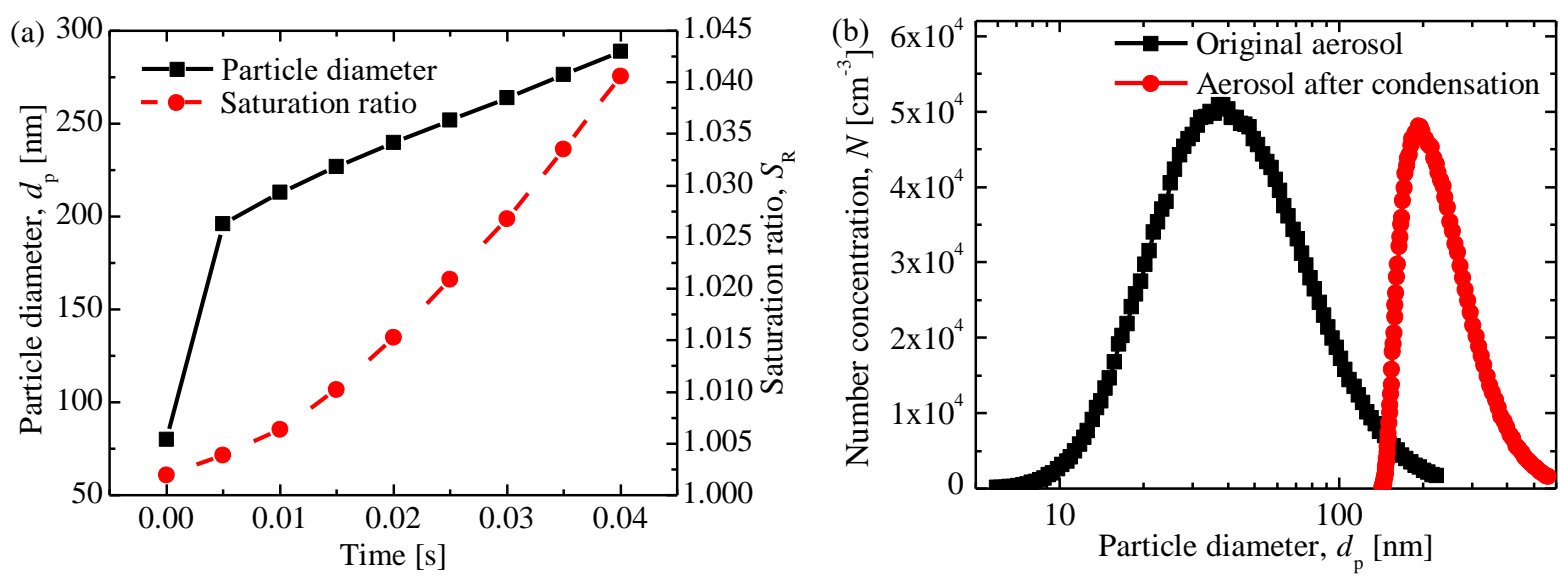

Fig. 6. (a) Evolution of saturation ratio and particle diameter in the cloud chamber during an adiabatic expansion (monodisperse aerosol, $\left.d_{\mathrm{p}}=80 \mathrm{~nm}, N=10^{6} \mathrm{~cm}^{-3}\right)$ and (b) growth of polydisperse aerosol $(N=$ $2.2 \times 10^{6} \mathrm{~cm}^{-3}, \bar{d}_{\mathrm{pg}}=41 \mathrm{~nm}, \sigma_{\mathrm{g}}=1.8 \mathrm{~nm}$ ) within adiabatic expansion model.

For a lognormal aerosol, the size distribution of droplets formed due to condensation in the cloud chamber causes a growth in the geometric mean diameter and a decrease in geometric standard deviation. Fig. $6 \mathrm{~b}$ shows the growth of a measured polydisperse aerosol with an initial geometric mean diameter of $\bar{d}_{\mathrm{pg}}=41 \mathrm{~nm}$ and geometric standard deviation of $\sigma_{\mathrm{g}}=1.8$. After a condensation growth in the cloud chamber, the geometric mean diameter increases to $\bar{d}_{\mathrm{pg}}=212$ $\mathrm{nm}$ and the standard deviation decreases to $\sigma_{\mathrm{g}}=1.3$. The growth of smaller particles in polydisperse aerosol is much larger than that for larger ones owing to the $\propto 1 / d_{\mathrm{p}}$ growth of particles in the continuum regime. The growth was modelled for all measured particle distributions used within this study, resulting in a 3.3 - 4.5 times increase in geometric mean diameter and narrowing of the geometric standard deviation by $16 \%$ to $26 \%$, as shown in the table in the supporting information.

\subsection{Light extinction in the cloud chamber}

In the device shown in Fig. 1, the photocurrent output from the photodiode is proportional to the sensed light intensity. The relation between this current and the size distribution of aerosol is described by Eqns. (15) - (18). We conducted experiments to verify this relation in conjunction with the isentropic model.

Figure 7 a shows the light extinction resulting from the cloud formation due to water vapor condensation onto $\mathrm{NaCl}$ aerosol particles in the cloud chamber and a comparison with the result predicted by the isentropic model. A fitting of the experimental results using the functional form of Eqn. (15) is also provided (standard error 0.00176), which results in a best fit of

$$
I / I_{0}=e^{-0.022 \sigma_{e}}
$$

thus indicating an effective length of $L_{\mathrm{b}}=0.022 \mathrm{~m}$. While in our cloud chamber, the measured physical length of the chamber between the photodetector and light source is $L_{\mathrm{b}}=0.042 \mathrm{~m}$, 
indicating that our actual change in measured intensity is $47.6 \%$ of that of the theoretical maximum. The likely loss of resolving power may due to internal reflections and multiscattering within the cloud chamber that increases the non-collimated light incident on the detector. For the length of the scatting volume in our cloud chamber $(0.042 \mathrm{~m})$ and a total number concentration of $10^{13} / \mathrm{m}^{3}$, we calculate the average number of scatting events to be $\sim 0.95$ for particles with diameter of $600 \mathrm{~nm}$. Resolving power may also be limited by the undersampling of the relatively large particles during the expansion which is not considered in the model. There are two $90^{\circ}$ bends with a diameter of $1.5 \mathrm{~mm}$ in the expansion flow. The estimated maximum instantaneous speed of aerosol flow is $18.8 \mathrm{~m} / \mathrm{s}$. Using the maximum diameter (around $600 \mathrm{~nm}$ ) of the enlarged particles, the system has a Reynolds number $R e=2000$ and the Stokes number $S t=0.0875$. At these conditions the under-sampling effect is weak relative to scattering effects. Apart from the constant offset the theoretical response curve matches all of the measured data within $\pm 5 \%$, as indicated by the error band range shown in Fig. $7 \mathrm{a}$.
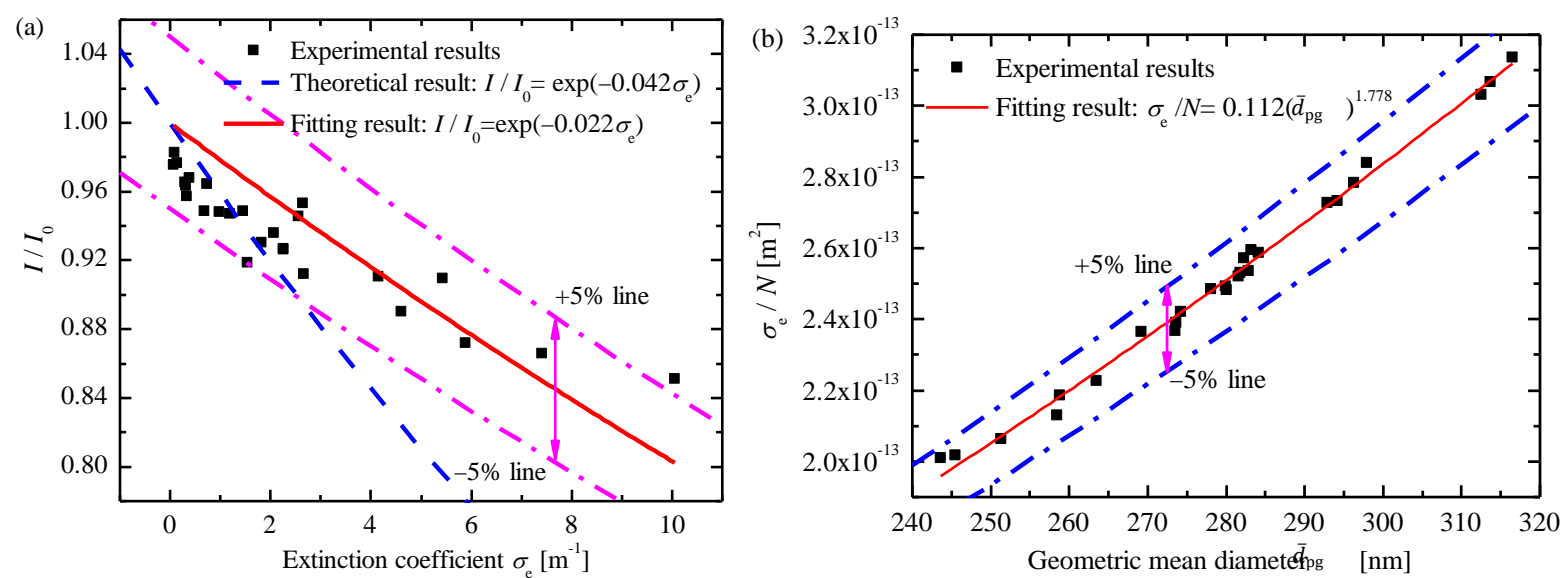

Fig. 7. (a) Measured light extinction (black squares) in the cloud chamber and a comparison with the theoretical results (blue dashed) and fitted results (red solid line). (b) Fitting of the relationship between the extinction coefficient and aerosol parameters.

The resulting scattered light intensity is a function of particle diameter and number concentration, which can be related to the geometric mean and standard deviation for a log normal distribution as in Eqn. (19). The resulting relationship allows us to determine

$$
\sigma_{\mathrm{e}} \approx 0.112 N\left(\bar{d}_{\mathrm{pg}}\right)^{1.778}
$$

as that shown in Fig. 7b. This remarkably consistent fit of the experimental data to the theoretical $\sigma_{\mathrm{e}}$ relationship, corroborates the relations developed by Jung and Kim (2007) and adopted here within Eqn. (17). The results indicate that particles are initially solid, and the liquid $\mathrm{H}_{2} \mathrm{O}$ condensate dominates the signal at the final stages of the light absorption. Studies of other particle chemistries (e.g. soot) show similar trends, but further work must be completed 
on a wide range of material chemistries to verify the impact that hydrophobic surfaces might have on the nature of these results.

Combining Eqns. (20) with (21), we can compare the calculated value of $I / I_{0}$ with the corresponding measured values. It displays a good agreement, as shown in Fig. 8, whereby the calculated $I / I_{0}$ is within $\pm 5 \%$ of the measured $I / I_{0}$.

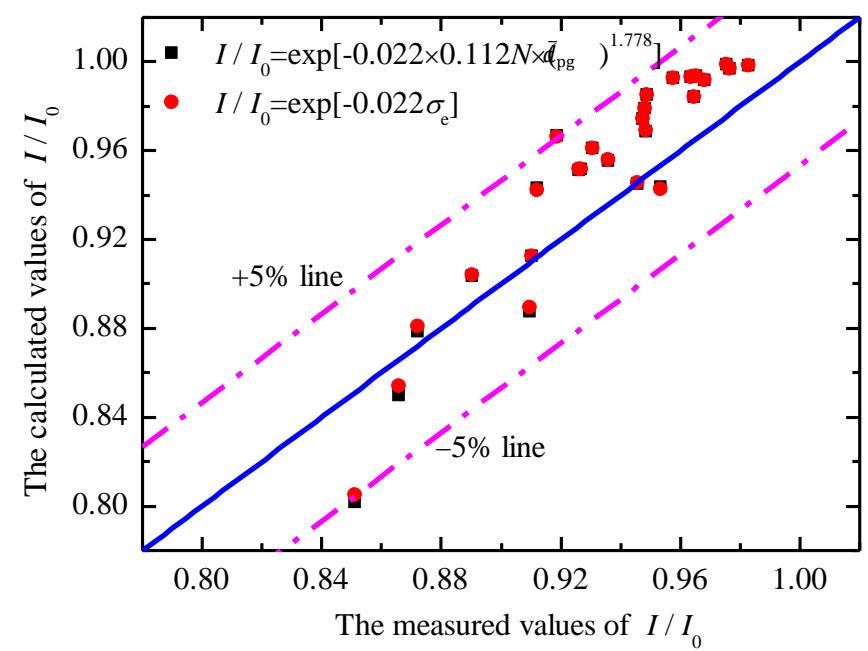

Fig. 8. Comparison of the measured values to calculated $I / I_{0}$ using expressions derived from Eqn. (20) and the combination of Eqns. (20) and (21).

The measured number concentration can be obtained by combining Eqns. (20) and (21), resulting in

$$
N_{\text {cal }}=\ln \left[I_{0} / I\right] /\left(0.022 \times 0.112\left(\bar{d}_{\mathrm{pg}}\right)^{1.778}\right)
$$

Error analysis, whereby the confidence intervals of $\pm 5 \%$ in Fig. 7 , is given by propagating through to provide meaningful error bands for the final measured number concentration. The $\pm 5 \%$ confidence interval for $I_{\mathrm{o}} / I$ from Fig. 7a results in $\ln \left[0.95 I_{0} / I\right] / 0.028<\sigma_{\mathrm{e}}<$ $\ln \left[1.05 I_{0} / I\right] / 0.022$. Similarly, for that in Fig. $7 \mathrm{~b}$, the fitted results satisfy $0.95 \times$ $0.112\left(\bar{d}_{\mathrm{pg}}\right)^{1.778}<\sigma_{\mathrm{e}} / N<1.05 \times 0.112\left(\bar{d}_{\mathrm{pg}}\right)^{1.778}$. Combining the two intervals results in the combined confidence for total calculated number concentration from the cloud chamber

$$
\frac{1}{1.05} \frac{-\frac{\ln \left[I / I_{0}\right]}{0.022}}{0.112\left(\bar{d}_{\mathrm{pg}}\right)^{1.778}}+\frac{\frac{\ln [0.95]}{0.022}}{1.05 \times 0.112\left(\bar{d}_{\mathrm{pg}}\right)^{1.778}}<N<\frac{1}{0.95} \frac{-\frac{\ln \left[I / I_{0}\right]}{0.022}}{0.112\left(\bar{d}_{\mathrm{pg}}\right)^{1.778}}+\frac{\frac{\ln [1.05]}{0.022}}{0.95 \times 0.112\left(\bar{d}_{\mathrm{pg}}\right)^{1.778}} .
$$

The range of the calculated values of number concentration can be obtained by the substitution of the term in Eqn. (22) with the measured values, namely, the calculated values should be within the uncertainty range

$$
\frac{N_{\mathrm{CPC}}}{1.05}+\frac{\ln [0.95]}{0.0026\left(\bar{d}_{\mathrm{pg}}\right)^{1.996}}<N<\frac{N_{\mathrm{CPC}}}{0.95}+\frac{\ln [1.05]}{0.0023\left(\bar{d}_{\mathrm{pg}}\right)^{1.996}} .
$$

Figure 9 shows the resulting calculated number concentration as measured by the cloud chamber (ordinate) compared to the number concentration as measured by the reference CPC 
(abscissa). In Fig. 9, $\bar{d}_{\mathrm{pg}, \mathrm{m}}$ and $\bar{N}_{\mathrm{cpc}}$ are the geometric mean diameter of aerosol particles after condensation and the mean value of the measured number concentration by CPC before condensation (measured in parallel by the SMPS), respectively. The difference in using a single mean $\bar{d}_{\mathrm{pg}, \mathrm{m}}=280 \mathrm{~nm}$ for all calculated results, versus using the individual modelled final $\bar{d}_{\mathrm{pg}}$ after growth for each experimental condition showed little difference. The similarity between the use of individual and mean values results from the slowed growth of large droplets during condensation, causing a homogenization of droplet diameters as they grow, as is typical in CPCs as well. The fitted functions $\left(\mathrm{R}^{2}>0.99\right)$ for the error band corresponding to Eqn. (23) for the range of measured $\bar{d}_{\mathrm{pg}}$ and $\bar{N}_{\mathrm{cpc}}$ is given by

$$
0.95 N_{\text {Calc }}-8.8 \times 10^{12} \mathrm{~m}^{-3}<N_{\text {CPC }}<1.05 N_{\text {Calc }}+9.2 \times 10^{12} \mathrm{~m}^{-3} .
$$

We find that the measured values largely fall within these limits with only two measured data points falling out of this range.

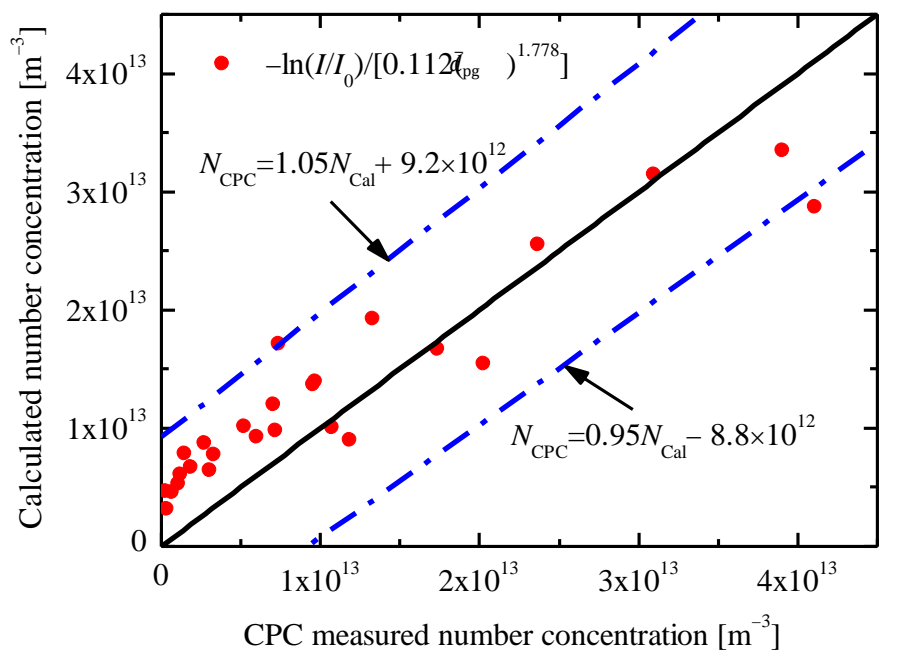

Fig. 9. Comparison of the calculated value of number concentration with the measured concentrations.

The overall results of calculated number concentration from the cloud chamber device is in general agreement $\left(\mathrm{R}^{2}=0.88\right)$ with the $\mathrm{CPC}$ reference instrument. The deviation in cloud chamber measurements from the reference CPC-measured concentrations demonstrates a distinctive trend where at low concentrations there is bias of higher measured concentration, near the upper bounds of experimental error. Because the linear offset of the calculated experimental error bands is relatively high $\left(\sim \pm 9 \times 10^{6} \mathrm{~cm}^{-3}\right)$ the limit of detection is higher than what is required for ambient sensing of aerosols, where concentrations of $10^{3} \mathrm{~cm}^{-3}$ are often measured. Nonetheless the overall trend for measured concentrations with the cloud chamber are in reasonable alignment with the CPC measured concentrations over the range of tested conditions. The current device is suitably accurate at high concentrations $\left(>10^{7} \mathrm{~m}^{-3}\right)$, which are 
typically found in fire detection or emissions measurements (e.g. combustion or automotive emissions).

The lower size detection limit of the cloud chamber can be estimated by interpolating the cumulative distribution of aerosol particles after condensation according to the difference of the total number concentrations. This lower limit locates in between $22.6 \mathrm{~nm}$ and $36.0 \mathrm{~nm}$ with a mean of $27.8 \mathrm{~nm}$ and a standard deviation of $3.6 \mathrm{~nm}$.

Further work could seek to increase sensitivity at lower number concentrations through better design of the inlet pathway for the aerosol, particularly through valving which has not been optimized for aerosol transport and is likely to have high diffusional losses. Further changes in valve timing and system geometry are promising means of increasing the saturation ratios, and thus signal intensity for low concentrations should ambient applications be desired.

\section{Conclusions}

Models based on isentropic and isenthalpic expansion were derived for an adiabatic expansion process in a cloud chamber whose volume is comparable with the connected buffer tank. These models can predict the time evolution of temperature, saturation ratio, particle growth, and the resultant light extinction that take place in the cloud chamber during expansion. A laboratory cloud chamber was fabricated and experiments using $\mathrm{NaCl}$ aerosol particles as the condensation nucleus were conducted. After the initial conditions of the adiabatic process were determined, model calculation was carried out. The relaxation factors for both of the two models were fixed according to the experimental results of temperature evolution in the buffer tank. Then the corrected models were used to predicted the temperature evolution in the cloud chamber. The results show that the model based on isentropic expansion in better agreement with the system physics than models based on isenthalpic behaviour. The isentropic model predictions suggested that the temperature in the cloud chamber drops $0.58{ }^{\circ} \mathrm{C}$ during the adiabatic expansion within $40 \mathrm{~ms}$, and accordingly, the saturation ratio attains 1.035 and the particles grow nearly 3 times for an initial diameter of $80 \mathrm{~nm}$ owning to condensation. For an aerosol with lognormal distribution originally, the predicted size distribution of droplets formed due to condensation in the cloud chamber are also lognormal. The geometric mean diameter grew more than 5 times and the size distribution was narrower. Furthermore, the extent of growth of smaller particles in polydisperse aerosol is much greater than that for larger particle diameters. The isentropic model also shown reasonable results for the light extinction coefficients.

Comparisons of the measured performance of the low-cost cloud chamber show strong agreement with the system physics and reference instruments, with relative error in measured 
extinction coefficients and signal intensities of $\pm 5 \%$. The propagation of error to the cloud chamber measured number concentrations resulted in the majority of points fitting within the calculated error band. The lower limit of detection for the device is hampered by the linear offset for propagated error $\left(\sim \pm 9 \times 10^{6} \mathrm{~cm}^{-3}\right)$. Nonetheless the strong correlation of measured and reference particle number concentrations $\left(\mathrm{R}^{2}=0.88\right)$ give promise for the low-cost device to find applications in high particle concentration environments, such as emissions detection. Further design improvements are possible, as guided by the underlying physics for improved signal to noise ratio at low concentrations by achieving higher saturation ratios upon expansion.

\section{Acknowledgements}

This work was supported by the State Scholarship Fund from China Scholarship Council.

\section{References}

[1] G. Oberdörster, E. Oberdörster, J. Oberdörster, Nanotoxicology: an emerging discipline evolving from studies of ultrafine particles, Environmental Health Perspectives 113 (2005) 823.

[2] H. -L. Kim, J. Han, S. -M. Lee, H. -B. Kwon, J. Hwang, Y. -J. Kim, MEMS-based particle detection system for measuring airborne ultrafine particles, Sensor Actuat A- Phys, (2018) $283235-244$.

[3] U.S. EPA, Integrated Science Assessment for Particulate Matter. 2009.

[4] T. Tajiri, K. Yamashita, M. Murakami, A. Saito, K. Kusunoki, N. Orikasa, L. Lilie, A novel adiabatic-expansion-type cloud simulation chamber. J. Meteorol. Soc. Jap. 91 (2013) 687704.

[5] L. Ahlm, T. Yli-Juuti, S. Schobesberger, A. P. Praplan, J. Kim, O.-P. Tikkanen, M. J. Lawler, J. N. Smith, J. Trostl, J. C. Acosta Navarro, U. Baltensperger, F. Bianchi, N. M. Donahue, J. Duplissy, A. Franchin, T. Jokinen, Keskinen, H. J. Kirkby, A. Kurten, A. Laaksonen, K. Lehtipalo, T. Petaja, F. Riccobono, M. P. Rissanen, L. Rondo, S. Schallhart, M. Simon, P. M. Winkler, D. R. Worsnop, A. Virtanen, I. Riipinen, Modeling the thermodynamics and kinetics of sulfuric acid-dimethylamine-water nanoparticle growth in the CLOUD chamber. Aerosol Sci. Tech. 50 (2016) 1017-1032.

[6] N. N. Das Gupta, S. K. Ghosh, A report on the wilson cloud chamber and its applications in physics. Rev. Mod. Phys. 18(2) (1946) 225-290.

[7] C. Mori, Visibility of the growth direction of an alpha-particle track in a diffusion cloud chamber. J. Nucl. Sci. Tech. 51 (2014) 196-200. 
[8] R. Wagner, O. Möhler, H. Saathoff, M. Schnaiter, T. Leisner, New cloud chamber experiments on the heterogeneous ice nucleation ability of oxalic acid in the immersion mode. Atmos. Chem. Phys. 11 (2011) 2083-2110.

[9] H. R. Smith, P. J. Connolly, A. J. Baran, E. Hesse, A. R. D. Smedley, A. R. Webb, Cloud chamber laboratory investigations into scattering properties of hollow ice particles. J. Quant. Spectrosc. Rad. Trans. 157 (2015) 106-118.

[10]B. Wang, D. A. Knopf, S. China, B. W. Arey, T. H. Harder, M. K. Gillesc, A. Laskina, Direct observation of ice nucleation events on individual atmospheric particles. Phys. Chem. Chem. Phys. 18 (2016) 29721.

[11]N. Sarnela, T. Jokinen, J. Duplissy, C. Yan, T. Nieminen, M. Ehn, S. Schobesberger, M. Heinritzi, S. Ehrhart, K. Lehtipalo, J. Tröstl, M. Simon, A. Kürten, M. Leiminger, M. J. Lawler, M. P. Rissanen, F. Bianchi, A. P. Praplan, J. Hakala, A. Amorim, M. Gonin, A. Hansel, J. Kirkby, J. Dommen, J. Curtius, J. N. Smith, T. Petäjä, D. R. Worsnop, M. Kulmala, N. M. Donahue, M. Sipilä, Measurement-model comparison of stabilized Criegee intermediate and highly oxygenated molecule production in the CLOUD chamber. Atmos. Chem. Phys. 18 (2018) 2363-2380.

[12]L. Nichman, C. Fuchs, E. Järvinen, K. Ignatius, N. F. Höppel, A. Dias, M. Heinritzi, M. Simon, J. Tröstl, A. C. Wagner, R. Wagner, C. Williamson, C. Yan, P. J. Connolly, J. R. Dorsey, J. Duplissy, S. Ehrhart, C. Frege, H. Gordon, C. R. Hoyle, T. B. Kristensen, G. Steiner, N. M. Donahue, R. Flagan, M. W. Gallagher, J. Kirkby, O. Möhler, H. Saathoff, M. Schnaiter, F. Stratmann, A. Tomé, Phase transition observations and discrimination of small cloud particles by light polarization in expansion chamber experiments. Atmos. Chem. Phys. 16 (2016) 3651-3664.

[13]J. P. Gollub, I. Chabay, W. H. Flygare, Optical heterodyne measurement of cloud droplet size distributions. Appl. Optics 12(12) (1973) 2838-2842.

[14]W. A. Hoppel, G. M. Frick, J. W. Fitzgerald, B. J. Wattle, A cloud chamber study of the effect that nonprecipitating water clouds have on the aerosol size distribution. Aerosol Sci. Tech., 20 (1994) 1-30.

[15]W. P. Arnott, C. Schmitt, Y. Liu, J. Hallett, Droplet size spectra and water vapor concentration of laboratory water clouds: inversion of Fourier transform infrared (5005000cm-1) optical-depth measurement. Appl. Optics 36(21) (1997) 5205-5216.

[16]D. Zhang, K. F. Moore, R. R. Friedl, M. -T. Leu, Design and characterization of a horizontal thermal gradient cloud condensation nucleus spectrometer. J. Aerosol Sci. 39(1) (2008) 30-39. 
[17]S. N. Vâjâiac, V. Filip, S. Ștefan, A. Boscornea, Assessing the size distribution of droplets in a cloud chamber from light extinction data during a transient regime. J. Atmos. Sol.-Terr. Phys. 109 (2014) 29-36.

[18]M. Schnaiter, S. Büttner, O. Möhler, J. Skrotzki, M.Vragel, R. Wagner, Influence of particle size and shape on the backscattering linear depolarisation ratio of small ice crystals - cloud chamber measurements in the context of contrail and cirrus microphysics. Atmos. Chem. Phys. 2012 (2012) 10465-10484.

[19]C. T. R. Wilson, The effect of Rontgen's rays on cloudy condensation. Pro. Roy. Soc. London 59 (1895) 338-339.

[20]F. Utheza, F. Garnier, Numerical investigation of the motion of a growing droplet in a thermal diffusion cloud chamber. J. Aerosol Sci. 34 (2003) 993-1007.

[21]O. Möhler, O. Stetzer, S. Schaefers, C. Linke, M. Schnaiter, R. Tiede, H. Saathoff, M. Krämer, A. Mangold, P. Budz, P. Zink, J. Schreiner, K. Mauersberger, W. Haag, B. Kärcher, U. Schurath, Experimental investigation of homogeneous freezing of sulphuric acid particles in the aerosol chamber AIDA. Atmos. Chem. Phys. 3 (2003) 211-223.

[22]P. E. Wagner, R. Strey, Homogeneous nucleation rates of water vapor measured in a two-piston expansion chamber. J. Chem. Phy. 85 (1981) 2694-2698.

[23]A. Fladerer, R. Strey, Growth of homogeneously nucleated water droplets: A quantitative comparison of experiment and theory. Atmos Res. 65 (2003) 161-187.

[24]P. M. Winkler, A. Vrtala, R. Rudolf, P. E. Wagner, I. Riipinen, T. Vesala, K. E. J. Lehtinen, Y. Viisanen, M. Kulmala, Condensation of water vapor: Experimental determination of mass and thermal accommodation coefficients. J. Geophys. Res. Atmos. 111 (2006) D19202.

[25]N. Moteki, Y. Kondo, A new theoretical method for calculating temperature and water vapor saturation ratio in an expansion cloud chamber. J. Geophys. Res. Atmos. 18 (2013) 6633-6642.

[26]D. A. Gubaidullin, P. P. Ossipov, A. A. Abdyushev, Simulation of aerosol distribution in hyperbolic resonator. App. Math. Model. 622019 181-193.

[27]S. S. Paramashivan, J. Mathew, S. Mahadevan, Mathematical modeling of aerosol emission from die sinking electrical discharge machining process. 36 (2012) 14931503.

[28]A. Wexler, Vapor pressure formulation for water in range 0 to $100{ }^{\circ} \mathrm{C}, \mathrm{A}$ revision. National Bureau Stand. A: Phys. Chem. 80A(5\&6) (1976) 775-785. 
[29]W. C. Hinds, Aerosol Tehnology, Properties, Behavior, and Measurement of Airborne Particles. New York: John Wiley \&Sons, Inc, 1999, (Chapter 13 and 16)

[30]D. T. Shaw, Fundamentals of Aerosol Science. New York: Wiley, 1978.

[31]W. B. Tian, J. T. Sun, M. F. Ramli, W. Q. Yang, Adaptive selection of relaxation factor in landweber iterative algorithm. IEEE Sens. J. 17(21) (2017) 7029-7042.

[32]C. H. Jung, Y. P. Kim, Technical note: particle extinction coefficient for polydispersed aerosol using a harmonic mean type general approximated solution. Aerosol Sci. Tech. 41 (2007) 994-1001. 
Table 1. List of Symbols

\begin{tabular}{|c|c|c|}
\hline Symbols & Descriptions & Units \\
\hline$c_{\mathrm{p}}$ & Specific heat capacity at constant pressure & $\mathrm{J} \mathrm{K}^{-1} \mathrm{~mol}^{-1}$ \\
\hline$d_{\mathrm{p}}$ & Diameter of aerosol particles & $\mathrm{nm}$ \\
\hline$d_{\mathrm{v}}$ & Effective diameter of water molecules, $4.0 \times 10^{-10}$ & $\mathrm{~m}$ \\
\hline $\bar{d}_{\mathrm{pg}}$ & geometric mean diameter of aerosol particles & $\mathrm{nm}$ \\
\hline$D_{\mathrm{v}}$ & Diffusion coefficient of water vapor molecules in air, $0.25 \times 10^{-4}$ & $\mathrm{~m}^{2} \mathrm{~s}^{-2}$ \\
\hline$H$ & Enthalpy & $\mathrm{J} \mathrm{K}^{-1}$ \\
\hline$I$ & Light intensity traversing an aerosol & cd \\
\hline$I_{0}$ & Light intensity incident on aerosol & cd \\
\hline$k_{\mathrm{B}}$ & Boltzmann constant & $\mathrm{J} \mathrm{K}^{-1}$ \\
\hline$K_{\mathrm{n}}$ & Knudsen Number & - \\
\hline$L$ & latent heat of condensation for water & $\mathrm{J} \mathrm{mol}^{-1}$ \\
\hline$L_{\mathrm{b}}$ & path length of the light beam & $\mathrm{m}$ \\
\hline$m$ & Mass of water molecules, $2.992 \times 10^{-26}$ & $\mathrm{~kg}$ \\
\hline$m_{\mathrm{p}}$ & Mass of the dissolved particles & $\mathrm{kg}$ \\
\hline$m_{\mathrm{r}}$ & Particle refractive index & - \\
\hline$M_{k}$ & The $k^{\text {th }}$ moment & $m^{k-3}$ \\
\hline$M_{\mathrm{s}}$ & Molecular weight of particle material & $\mathrm{kg}$ \\
\hline$n$ & Molar quantity of substance & mol \\
\hline$\dot{n}$ & Molar flux of substance & mol \\
\hline$N$ & Number concentration of particles & $\mathrm{m}^{-3}$ \\
\hline$N_{\mathrm{A}}$ & Avogadro Constant & - \\
\hline$N_{\text {num }}$ & Number of particles in cloud chambers & - \\
\hline$p$ & Pressure & $\mathrm{Pa}$ \\
\hline$p_{\mathrm{d}}$ & Partial pressure of water vapor at the particle surface & $\mathrm{Pa}$ \\
\hline$p_{\text {sat }}$ & Saturation vapor pressure of water vapor & $\mathrm{Pa}$ \\
\hline$q$ & Number of ions each molecule of particles forms when it dissolves in water & - \\
\hline$Q_{\mathrm{e}}$ & Extinction efficiency & - \\
\hline$R$ & General ideal gas constant & $\mathrm{J} \mathrm{K}^{-1} \mathrm{~kg}^{-1}$ \\
\hline$R_{\mathrm{H}}$ & Relative humidity & $\%$ \\
\hline$S$ & Entropy & $\mathrm{J} \mathrm{K}^{-1}$ \\
\hline $\bar{S}$ & Specific entropy & $\mathrm{J} \mathrm{K}^{-1} \mathrm{~mol}^{-1}$ \\
\hline$S_{\mathrm{R}}$ & Saturation ratio of water vapor & - \\
\hline$T$ & Temperature & $\mathrm{K}$ \\
\hline$T_{\mathrm{d}}$ & Temperature at the particle surface & $\mathrm{K}$ \\
\hline u & Volume of vessels & $\mathrm{m}^{3}$ \\
\hline$V_{\mathrm{m}}$ & Volume of water molecules & $\mathrm{m}^{3}$ \\
\hline$\alpha_{\mathrm{c}}$ & Condensation coefficient, 0.04 [Hinds, 1999] & - \\
\hline$\Delta t$ & Time period from $i$ to $i+1$ & $\mathrm{~s}$ \\
\hline$\varnothing$ & Fuchs correction factor & - \\
\hline$\gamma$ & Surface tension of water & $\mathrm{N} \mathrm{m}^{-1}$ \\
\hline$\eta$ & Relaxation factor & - \\
\hline$\dot{\lambda}$ & Mean free path & $\mathrm{m}$ \\
\hline$\lambda_{\mathrm{L}}$ & Wavelength of light & $\mathrm{nm}$ \\
\hline$\sigma_{\mathrm{e}}$ & Extinction coefficient & $\mathrm{m}^{-1}$ \\
\hline$\sigma_{\mathrm{g}}$ & Standard deviation of aerosol particle distribution & - \\
\hline$\rho_{\mathrm{p}}$ & Density of particle material & $\mathrm{kg} \mathrm{m}^{-3}$ \\
\hline$\rho_{\ell}$ & Density of water, 1000 & $\mathrm{~kg} \mathrm{~m}^{-3}$ \\
\hline
\end{tabular}


Table 2. List of subscripts and superscripts

\begin{tabular}{clc}
\hline Subscripts & \multicolumn{1}{c}{ Meanings } & Applied Variables \\
\hline $\mathrm{a}$ & Dry air gas in aerosol & $c_{\mathrm{p}}, n, S, \bar{s}, p$ \\
$\mathrm{~B}$ & Buffer tank & $n, S, \bar{s}, p, T, V$ \\
$\mathrm{C}$ & Cloud chamber & $n, S, \bar{s}, p, T, V$ \\
$\mathrm{C} \rightarrow \mathrm{B}$ & Substance entering the buffer tank from the cloud chamber & $\dot{n}$ \\
$\mathrm{~d}$ & Particle surface & $p, \lambda, d_{\mathrm{p}}$ \\
$f$ & The finial step of the calculation cycle & $d_{\mathrm{p}}, K_{\mathrm{n}}, n, N_{\mathrm{num}}, p, p_{\mathrm{d}}, p_{\text {sat }}, S, \bar{s}$, \\
$i, i+1$ & Integers representing time increment during expansion & $S_{\mathrm{R}}, T, T_{\mathrm{d}}, \emptyset, \lambda$ \\
$j$ & Ordinal number of the size interval & $d_{\mathrm{p}}, N, N_{\mathrm{num}}, \widehat{N}$ \\
$k$ & Order of moment & $M$ \\
$\ell$ & Liquid water & $c_{\mathrm{p}}, n, S, \bar{s}$ \\
$\mathrm{~S}$ & Surroundings & $p, T, N$ \\
$\mathrm{v}$ & Water vapor in aerosol & $c_{\mathrm{p}}, n, S, \bar{s}, p$ \\
$\mathrm{v} \rightarrow \ell$ & Substance condensing onto aerosol particles & $\dot{n}$ \\
\hline & &
\end{tabular}


Table 3. Coefficients defined during the derivation of equations (11) and (13)

\begin{tabular}{|c|c|}
\hline Coefficients & Expressions \\
\hline$a_{\mathrm{C}_{i}}$ & $c_{\mathrm{p}, \mathrm{v}} n_{\mathrm{C}, \mathrm{v}_{i}}+c_{\mathrm{p}, \mathrm{a}} n_{\mathrm{C}, \mathrm{a}_{i}}$ \\
\hline$a_{\mathrm{B}_{i}}$ & $c_{\mathrm{p}, \mathrm{v}} n_{\mathrm{B}, \mathrm{v}_{i}}+c_{\mathrm{p}, \mathrm{a}} n_{\mathrm{B}, \mathrm{a}_{i}}$ \\
\hline$b_{\mathrm{a}_{i}}$ & $n_{\mathrm{C}, \mathrm{v}_{i}}\left(n_{\mathrm{B}, \mathrm{a}_{i}}+n_{\mathrm{C}, \mathrm{a}_{i}}\right)-n_{\mathrm{C}, \mathrm{a}_{i}} \dot{n}_{\mathrm{C}, \mathrm{v} \rightarrow \ell_{i}}$ \\
\hline$b_{v_{i}}$ & $n_{\mathrm{C}, \mathrm{v}_{i}}\left(n_{\mathrm{B}, \mathrm{v}_{i}}+n_{\mathrm{C}, \mathrm{v}_{i}}\right)-n_{\mathrm{C}, \mathrm{v}_{i}} \dot{n}_{\mathrm{C}, \mathrm{v} \rightarrow \ell_{i}}$ \\
\hline$b_{i}$ & $p_{\mathrm{C}_{i+1}} V_{\mathrm{C}} / R$ \\
\hline$c_{\mathrm{a}_{i}}$ & $b_{i} n_{\mathrm{C}, \mathrm{a}_{i}}$ \\
\hline$c_{\mathrm{v}_{i}}$ & $b_{i} n_{\mathrm{C}, \mathrm{v}_{i}}$ \\
\hline$d_{i}$ & $a_{\mathrm{C}_{i}}+a_{\mathrm{B}_{i}}+\frac{p_{\mathrm{C}_{i+1}}-p_{\mathrm{C}_{i}}}{T_{\mathrm{C}_{i}}} V_{\mathrm{C}}+\frac{p_{\mathrm{B}_{i+1}}-p_{\mathrm{B}_{i}}}{T_{\mathrm{B}_{i}}} V_{\mathrm{B}}+c_{\ell} n_{\mathrm{C}, \ell_{i}}-\left(R n_{\mathrm{C}_{i}}-a_{\mathrm{C}_{i}}\right)\left(1-\frac{\dot{n}_{\mathrm{C}, \mathrm{v} \rightarrow \ell_{i}}}{n_{\mathrm{C}_{i}}}\right)$ \\
\hline $\begin{array}{l}e_{i} \\
f_{1_{i}} \\
f_{2_{i}} \\
f_{\mathrm{c}_{i}}\end{array}$ & $\begin{array}{c}\left(a_{\mathrm{C}_{i}}+c_{\ell} n_{\mathrm{C}, \ell_{i}}\right) / T_{\mathrm{C}_{i}} \\
{\left[b_{\mathrm{v}_{i}}+b_{\mathrm{a}_{i}}\left(1-n_{\mathrm{C}_{i}} / n_{\mathrm{C}, \mathrm{v}_{i}}\right)\right] \dot{n}_{\mathrm{C}, \mathrm{v} \rightarrow \ell_{i}}} \\
\left(1-n_{\mathrm{C}_{i}} / n_{\mathrm{C}, \mathrm{v}_{i}}\right)\left(\dot{n}_{\mathrm{C}, \mathrm{v} \rightarrow \ell_{i}}\right)^{2} \\
a_{\mathrm{C}_{i}}\left(1-\dot{n}_{\mathrm{C}, \mathrm{v} \rightarrow \ell_{i}} / n_{\mathrm{C}_{i}}\right)\end{array}$ \\
\hline$g_{1_{i}}$ & $b_{i}\left(b_{\mathrm{v}_{i}}+b_{\mathrm{a}_{i}}\right)-\left[c_{\mathrm{v}_{i}}+c_{\mathrm{a}_{i}}\left(1-n_{\mathrm{C}_{i}} / n_{\mathrm{C}, \mathrm{v}_{i}}\right)\right] \dot{n}_{\mathrm{C}, \mathrm{v} \rightarrow \ell_{i}}$ \\
\hline$g_{2_{i}}$ & $b_{i}\left(2-n_{\mathrm{C}_{i}} / n_{\mathrm{C}, \mathrm{v}_{i}}\right) \dot{n}_{\mathrm{C}, \mathrm{v} \rightarrow \ell_{i}}$ \\
\hline$g_{C_{i}}$ & $\dot{n}_{\mathrm{C}, \mathrm{v} \rightarrow \ell_{i}} L-p_{\mathrm{C}_{i+1}} V_{\mathrm{C}}\left(1-a_{\mathrm{C}_{i}} / R n_{\mathrm{C}_{i}}\right)$ \\
\hline$h_{1 i}$ & $-b_{i}\left(c_{\mathrm{v}_{i}}+c_{\mathrm{a}_{i}}\right)$ \\
\hline$h_{2_{i}}$ & $\left(b_{i}\right)^{2}$ \\
\hline$h_{\mathrm{B}_{i}}$ & $b_{i} R V_{\mathrm{C}} / n_{\mathrm{C}_{i}} V_{\mathrm{B}}$ \\
\hline$h_{\mathrm{C}_{i}}$ & $R V_{\mathrm{C}}\left(n_{\mathrm{C}_{i}}-\dot{n}_{\mathrm{C}, \mathrm{v} \rightarrow \ell_{i}}\right) / n_{\mathrm{C}_{i}} V_{\mathrm{B}}$ \\
\hline$l_{i}$ & $a_{\mathrm{B}_{i}} T_{\mathrm{B}_{i}}+\left(a_{\mathrm{C}_{i}}+c_{\ell} n_{\mathrm{C}, \ell_{i}}\right) T_{C_{i}}-\dot{n}_{\mathrm{C}, \mathrm{v} \rightarrow \ell_{i}} L-\frac{a_{\mathrm{C}_{i}} b_{i}}{n_{\mathrm{C}_{i}}}$ \\
\hline$r_{i}$ & $\left(n_{\mathrm{C}_{i}}+n_{\mathrm{B}_{i}}-\dot{n}_{\mathrm{C}, \mathrm{v} \rightarrow \ell_{i}}\right) R$ \\
\hline$A_{i}$ & $r_{i} f_{2_{i}}$ \\
\hline$B_{i}$ & $r_{i} g_{2_{i}}-p_{\mathrm{C}_{i+1}} V_{\mathrm{C}} f_{2_{i}}$ \\
\hline$C_{i}$ & $r_{i} h_{2 i}-g_{2_{i}}$ \\
\hline$D_{i}$ & $-p_{\mathrm{C}_{i+1}} V_{\mathrm{C}} h_{2_{i}}$ \\
\hline$E_{i}$ & $a_{\mathrm{B}_{i}} p_{\mathrm{B}_{i+1}} V_{\mathrm{B}} / T_{\mathrm{B}_{i}}$ \\
\hline$F_{i}$ & $p_{\mathrm{B}_{i+1}} V_{\mathrm{B}}$ \\
\hline$G_{i}$ & $a_{\mathrm{C}_{i}} b_{i} p_{\mathrm{B}_{i+1}} V_{\mathrm{B}} / n_{\mathrm{C}_{i}}$ \\
\hline$C_{i}^{1}$ & $e_{i} A_{i}$ \\
\hline$C_{i}^{2}$ & $e_{i} B_{i}-d_{i} A_{i}+f_{2 i} E_{i}$ \\
\hline$C_{i}^{3}$ & $e_{i} C_{i}-d_{i} B_{i}+g_{\mathrm{C}_{i}} A_{i}+g_{2_{i}} E_{i}+f_{2_{i}} f_{\mathrm{c}_{i}} F_{i}-f_{1_{i}} h_{\mathrm{C}_{i}} F_{i}$ \\
\hline$C_{i}^{4}$ & $e_{i} D_{i}-d_{i} C_{i}+g_{\mathrm{C}_{i}} B_{i}-f_{2_{i}} G_{i}+h_{2_{i}} E_{i}+g_{2_{i}} f_{\mathrm{C}_{i}} F_{i}-g_{1_{i}} h_{\mathrm{C}_{i}} F_{i}+f_{1_{i}} h_{\mathrm{B}_{i}} F_{i}$ \\
\hline$C_{i}^{5}$ & $-d_{i} D_{i}+g_{\mathrm{C}_{i}} C_{i}-g_{2_{i}} G_{i}+h_{2_{i}} f_{\mathrm{c}_{i}} F_{i}-h_{1_{i}} h_{\mathrm{C}_{i}} F_{i}+g_{1_{i}} h_{\mathrm{B}_{i}} F_{i}$ \\
\hline$C_{i}^{6}$ & $g_{\mathrm{C}_{i}} D_{i}-h_{2_{i}} G_{i}+h_{1_{i}} h_{\mathrm{B}_{i}} F_{i}$ \\
\hline$C_{i}^{7}$ & $\left(a_{\mathrm{C}_{i}} \frac{\dot{n}_{\mathrm{C}, \mathrm{v} \rightarrow \ell_{i}}}{n_{\mathrm{C}_{i}}}+c_{\ell} n_{\mathrm{C}, \ell_{i}}\right) r_{i}$ \\
\hline$C_{i}^{8}$ & $\left(a_{\mathrm{B}_{i}}+a_{\mathrm{C}_{i}}-a_{\mathrm{C}_{i}} \frac{\dot{n}_{\mathrm{C}, \mathrm{v} \rightarrow \ell_{i}}}{n_{\mathrm{C}_{i}}}\right) p_{\mathrm{B}_{i+1}} V_{\mathrm{B}}-\left(a_{\mathrm{C}_{i}} \frac{\dot{n}_{\mathrm{C}, \mathrm{v} \rightarrow \ell_{i}}}{n_{\mathrm{C}_{i}}}+c_{\ell} n_{\mathrm{C}, \ell_{i}}\right) p_{\mathrm{C}_{i+1}} V_{\mathrm{C}}-l_{i} r_{i}$ \\
\hline$C_{i}^{9}$ & $l_{i} p_{\mathrm{C}_{i+1}} V_{\mathrm{C}}-\frac{a_{\mathrm{C}_{i}} b_{i}}{n_{\mathrm{C}_{i}}} p_{\mathrm{B}_{i+1}} V_{\mathrm{B}}$ \\
\hline
\end{tabular}




\section{Appendix}

\section{A1. Model approach}

The model approach is given in Fig. A1. 


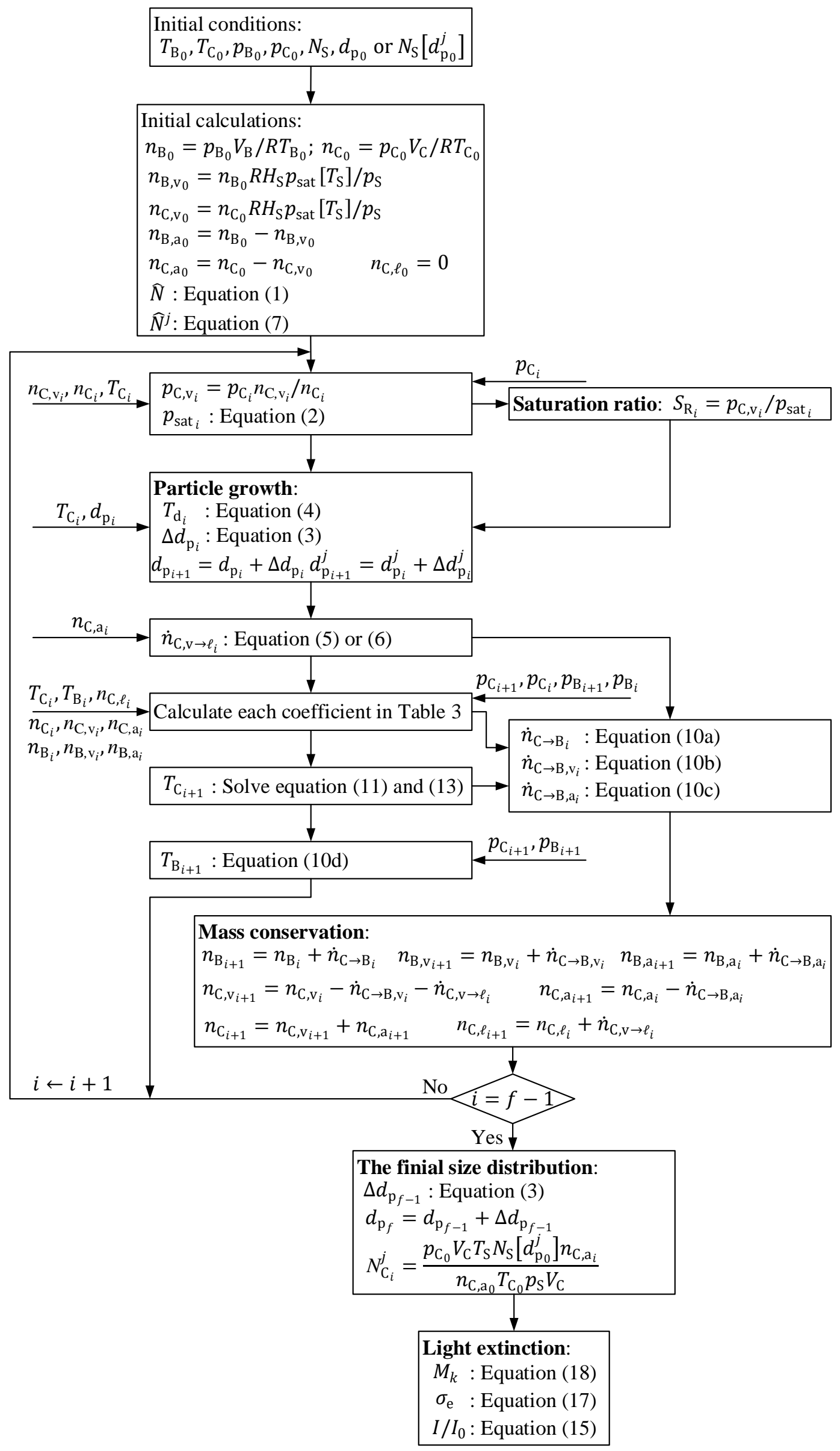

Fig. A1. Flow chat of model approach. 


\section{A2. Vapor Condensation}

In Eqn. (3b), $\phi_{i}$ is the Fuchs correction factor [27]

$$
\phi_{i}=\frac{1+K_{\mathrm{n}_{i}}}{1+1.71 K_{n_{i}}+1.33\left(K_{\mathrm{n}_{i}}\right)^{2}}
$$

and the Knudsen Number at time $i$ in cloud chamber is

$$
K_{\mathrm{n}_{i}}=\frac{2 \lambda_{i}}{d_{\mathrm{p}_{i}}}
$$

The saturation ratio $S_{\mathrm{R}_{i}}$ is

$$
S_{\mathrm{R}_{i}}=\frac{p_{\mathrm{C}, \mathrm{v}_{i}}}{p_{\mathrm{sat}_{i}}}
$$

The volume of water vapor condensing onto particles during the period from $i$ to $i+1$ is

$$
\dot{V}_{\mathrm{C}, \mathrm{v} \rightarrow \ell_{i}}=\frac{\pi}{6}\left(\left(d_{\mathrm{p}_{i}}+\Delta d_{\mathrm{p}_{i}}\right)^{3}-\left(d_{\mathrm{p}_{i}}\right)^{3}\right) N_{\mathrm{num}_{i}}
$$

where $N_{\text {num }_{i}}$ is the number of particles in the cloud chamber at the moment of $i$. We suppose particles disperse uniformly in cloud chamber. Then we find $N_{\text {num }_{i}}=\widehat{N} n_{\mathrm{C}, \mathrm{a}_{i}}$ and Eqn. (24) can be obtained.

\section{A3. Time evolution of temperature - Method based on isentropic expansion}

The total entropy at the time point of $i+1$ is

$$
\begin{aligned}
& S_{i+1}=\left(n_{\mathrm{B}, \mathrm{v}_{i}}+\dot{n}_{\mathrm{C} \rightarrow \mathrm{B}, \mathrm{v}_{i}}\right) \bar{s}_{\mathrm{B}, \mathrm{v}_{i+1}}\left(T_{\mathrm{B}_{i+1}}\right)+\left(n_{\mathrm{B}, \mathrm{a}_{i}}+\dot{n}_{\mathrm{C} \rightarrow \mathrm{B}, \mathrm{a}_{i}}\right) \bar{s}_{\mathrm{B}, \mathrm{a}_{i+1}}\left(T_{\mathrm{B}_{i+1}}\right)+\left(n_{\mathrm{C}, \ell_{i}}+\right. \\
& \left.\dot{n}_{\mathrm{C}, \mathrm{v} \rightarrow \ell_{i}}\right) \bar{s}_{\mathrm{C}, \ell_{i+1}}\left(T_{\mathrm{C}_{i+1}}\right)+\left(n_{\mathrm{C}, \mathrm{v}_{i}}-\dot{n}_{\mathrm{C} \rightarrow \mathrm{B}, \mathrm{v}_{i}}-\dot{n}_{\mathrm{C}, \mathrm{v} \rightarrow \ell_{i}}\right) \bar{s}_{\mathrm{C}, \mathrm{v}_{i+1}}\left(T_{\mathrm{C}_{i+1}}\right)+\left(n_{\mathrm{C}, \mathrm{a}_{i}}-\dot{n}_{\mathrm{C} \rightarrow \mathrm{B}, \mathrm{a}_{i}}\right) \bar{s}_{\mathrm{C}, \mathrm{a}_{i+1}}\left(T_{\mathrm{C}_{i+1}}\right)
\end{aligned}
$$

Applying isentropic conditions, $S_{i+1}=S_{i}$, to Eqn. (8) and (A5) with the result from Eqn. (9) a governing total system equation that includes the cloud chamber temperature $T_{\mathrm{C}_{i}}$ is given by,

$$
\begin{aligned}
& \frac{a_{\mathrm{B}_{i}}}{T_{\mathrm{B}_{i}}} T_{\mathrm{B}_{i+1}}-\left(a_{\mathrm{C}_{i}}+a_{\mathrm{B}_{i}}+\frac{p_{\mathrm{C}_{i+1}}-p_{\mathrm{C}_{i}}}{T_{\mathrm{C}_{i}}} V_{\mathrm{C}}+\frac{p_{\mathrm{B}_{i+1}}-p_{\mathrm{B}_{i}}}{T_{\mathrm{B}_{i}}} V_{\mathrm{B}}+c_{\ell} n_{\mathrm{C}, \ell_{i}}\right)+\left(a_{\mathrm{C}_{i}}+c_{\ell} n_{\mathrm{C}, \ell_{i}}\right) \frac{T_{\mathrm{C}_{i+1}}}{T_{\mathrm{C}_{i}}} \\
& \quad+\left[\left(c_{\mathrm{p}, \mathrm{v}} \dot{n}_{\mathrm{C} \rightarrow \mathrm{B}, \mathrm{v}_{i}}+c_{\mathrm{p}, \mathrm{a}} \dot{n}_{\mathrm{C} \rightarrow \mathrm{B}, \mathrm{a}_{i}}\right)-\frac{R V_{\mathrm{C}}}{V_{\mathrm{B}}}\left(\dot{n}_{\mathrm{C} \rightarrow \mathrm{B}, \mathrm{v}_{i} i} \frac{n_{\mathrm{B}, \mathrm{v}_{i+1}}}{n_{\mathrm{C}, \mathrm{v}_{i+1}}}+\dot{n}_{\mathrm{C} \rightarrow \mathrm{B}, \mathrm{a}_{i}} \frac{n_{\mathrm{B}, \mathrm{a}_{i+1}}}{n_{\mathrm{C}, \mathrm{a}_{i+1}}}\right)\right] \frac{T_{\mathrm{B}_{i+1}}}{T_{\mathrm{C}_{i+1}}} \\
& +R \dot{n}_{\mathrm{C} \rightarrow \mathrm{B}}-\left(c_{\mathrm{p}, \mathrm{v}} \dot{n}_{\mathrm{C} \rightarrow \mathrm{B}, \mathrm{v}_{i}}+c_{\mathrm{p}, \mathrm{a}} \dot{n}_{\mathrm{C} \rightarrow \mathrm{B}, \mathrm{a}_{i}}\right)+\dot{n}_{\mathrm{C}, \mathrm{v} \rightarrow \ell_{i}} \frac{L}{T_{\mathrm{C}_{i+1}}}=0
\end{aligned}
$$

where $V_{\mathrm{C}}$ and $V_{\mathrm{B}}$ are volumes of the cloud chamber and the connected buffer tank, $c_{\ell}$ is the specific heat capacity of liquid water, $L$ is the latent heat of condensation for water vapor, which is assumed to be approximately constant during the expansion, and $a_{\mathrm{B}_{i}}=c_{\mathrm{p}, \mathrm{v}} n_{\mathrm{B}, \mathrm{v}_{i}}+c_{\mathrm{p}, \mathrm{a}} n_{\mathrm{B}, \mathrm{a}_{i}}$, $a_{\mathrm{C}_{i}}=c_{\mathrm{p}, \mathrm{v}} n_{\mathrm{C}, \mathrm{v}_{i}}+c_{\mathrm{p}, \mathrm{a}} n_{\mathrm{C}, \mathrm{a}_{i}}$.

In order to solve Eqn. (A6), the following relations need to be used. Ideal gas state equations at time $i+1$ for the mixture gas in both buffer tank and cloud chamber are 


$$
\begin{aligned}
& p_{\mathrm{B}_{i+1}} V_{\mathrm{B}}=n_{\mathrm{B}_{i+1}} R T_{\mathrm{B}_{i+1}} \\
& p_{\mathrm{C}_{i+1}} V_{\mathrm{C}}=n_{\mathrm{C}_{i+1}} R T_{\mathrm{C}_{i+1}}
\end{aligned}
$$

Mass conservation equations for the substances in both of the vessels are

$$
\begin{aligned}
& n_{\mathrm{B}_{i+1}}=n_{\mathrm{B}_{i}}+\dot{n}_{\mathrm{C} \rightarrow \mathrm{B}_{i}} \\
& n_{\mathrm{B}, \mathrm{v}_{i+1}}=n_{\mathrm{B}, \mathrm{v}_{i}}+\dot{n}_{\mathrm{C} \rightarrow \mathrm{B}, \mathrm{v}_{i}} \\
& n_{\mathrm{B}, \mathrm{a}_{i+1}}=n_{\mathrm{B}, \mathrm{a}_{i}}+\dot{n}_{\mathrm{C} \rightarrow \mathrm{B}, \mathrm{a}_{i}} \\
& n_{\mathrm{C}, \mathrm{v}_{i+1}}=n_{\mathrm{C}, \mathrm{v}_{i}}-\dot{n}_{\mathrm{C} \rightarrow \mathrm{B}, \mathrm{v}_{i}}-\dot{n}_{\mathrm{C}, \mathrm{v} \rightarrow \ell_{i}} \\
& n_{\mathrm{C}, \mathrm{a}_{i+1}}=n_{\mathrm{C}, \mathrm{a}_{i}}-\dot{n}_{\mathrm{C} \rightarrow \mathrm{B}, \mathrm{a}_{i}} \\
& n_{\mathrm{C}, \ell_{i+1}}=n_{\mathrm{C}, \ell_{i}}+\dot{n}_{\mathrm{C}, \mathrm{v} \rightarrow \ell_{i}} \\
& n_{\mathrm{C}_{i+1}}=n_{\mathrm{C}, \mathrm{v}_{i+1}}+n_{\mathrm{C}, \mathrm{a}_{i+1}}
\end{aligned}
$$

where $n_{\mathrm{C}_{i+1}}$ in Eqn. (A15) just concerns with the gas mixture in the cloud chamber.

The incremental molar concentrations of water vapor and dry air are proportional to the ratio of the amount of each species to that of the mixture gas in the cloud chamber in the previous time step, respectively, namely,

$$
\begin{gathered}
\dot{n}_{\mathrm{C} \rightarrow \mathrm{B}, \mathrm{v}_{i}}=\frac{n_{\mathrm{C}, \mathrm{v}_{i}}}{n_{\mathrm{C}_{i}}} \dot{n}_{\mathrm{C} \rightarrow \mathrm{B}_{i}} \\
\dot{n}_{\mathrm{C} \rightarrow \mathrm{B}, \mathrm{a}_{i}}=\frac{n_{\mathrm{C}, \mathrm{a}_{i}}}{n_{\mathrm{C}_{i}}} \dot{n}_{\mathrm{C} \rightarrow \mathrm{B}_{i}}
\end{gathered}
$$

Using Eqs. (A15), (A12) and (A13), $n_{\mathrm{C}_{i}}=n_{\mathrm{C}, \mathrm{v}_{i}}+n_{\mathrm{C}, \mathrm{a}_{i}}$, and $\dot{n}_{\mathrm{C} \rightarrow \mathrm{B}_{i}}=\dot{n}_{\mathrm{C} \rightarrow \mathrm{B}, \mathrm{v}_{i}}+\dot{n}_{\mathrm{C} \rightarrow \mathrm{B}, \mathrm{a}_{i}}$, we have

$$
n_{\mathrm{C}_{i+1}}=n_{\mathrm{C}_{i}}-\dot{n}_{\mathrm{C} \rightarrow \mathrm{B}_{i}}-\dot{n}_{\mathrm{C}, \mathrm{v} \rightarrow \ell_{i}}
$$

Equations (10a)-(10c) can be obtained by the substitution of Eqs. (A18) into (A8), and the resultant one into Eqs. (A16) and (A17), respectively.

$$
\dot{n}_{\mathrm{C} \rightarrow \mathrm{B}_{i}}=n_{\mathrm{C}_{i}}-\frac{p_{\mathrm{C}_{i+1} V_{\mathrm{C}}}}{R T_{\mathrm{C}_{i+1}}}-\dot{n}_{\mathrm{C}, \mathrm{v} \rightarrow \ell_{i}}
$$

According to Eqs. (A7) and (A9), a substitution of Eqn. (10a) leads to

$$
T_{\mathrm{B}_{i+1}}=\frac{p_{\mathrm{B}_{i+1}} V_{\mathrm{B}}}{\left(n_{\mathrm{B}_{i}}+\dot{n}_{\mathrm{C} \rightarrow \mathrm{B}_{i}}\right) R}=\frac{p_{\mathrm{B}_{i+1} V_{\mathrm{B}}}}{\left(n_{\mathrm{B}_{i}}+n_{\mathrm{C}_{i}}-\dot{n}_{\mathrm{C}, \mathrm{v} \rightarrow \ell_{i}}-\frac{b_{i}}{T_{\mathrm{C}_{i+1}}}\right) R}
$$

Equation (10d) is obtained by the simplification of Eqn. (A20).

Substitution of expressions (10a)-(10d) into Eqn. (A6) gives

$$
\begin{aligned}
& -\left[a_{\mathrm{C}_{i}}+a_{\mathrm{B}_{i}}+\frac{p_{\mathrm{C}_{i+1}}-p_{\mathrm{C}_{i}}}{T_{\mathrm{C}_{i}}} V_{\mathrm{C}}+\frac{p_{\mathrm{B}_{i+1}}-p_{\mathrm{B}_{i}}}{T_{\mathrm{B}_{i}}} V_{\mathrm{B}}+c_{\ell} n_{\mathrm{C}, \ell_{i}}-\left(R n_{\mathrm{C}_{i}}-a_{\mathrm{C}_{i}}\right)\left(1-\frac{\dot{n}_{\mathrm{C}, \mathrm{v} \rightarrow \ell_{i}}}{n_{\mathrm{C}_{i}}}\right)\right]+ \\
& \frac{a_{\mathrm{C}_{i}}+c_{\ell} n_{\mathrm{C}, \ell_{i}}}{T_{\mathrm{C}_{i}}} T_{\mathrm{C}_{i+1}}+a_{\mathrm{C}_{i}}\left(1-\frac{c_{\ell} n_{\mathrm{C}, \ell_{i}}}{n_{\mathrm{C}_{i}}}\right) \frac{T_{\mathrm{B}_{i+1}}}{T_{\mathrm{C}_{i+1}}}-\frac{R V_{\mathrm{C}}}{V_{\mathrm{B}} n_{\mathrm{C}_{i}}}\left(n_{\mathrm{C}_{i}} T_{\mathrm{C}_{i+1}}-b_{i} n_{\mathrm{C}_{i}}-\right.
\end{aligned}
$$




$$
\begin{aligned}
& \left.n_{\mathrm{C}, \ell_{i}} T_{\mathrm{C}_{i+1}}\right)\left(n_{\mathrm{C}, \mathrm{v}_{i}} \frac{n_{\mathrm{B}, \mathrm{v}_{i+1}}}{n_{\mathrm{C}, \mathrm{v}_{i+1}}}+n_{\mathrm{C}, \mathrm{a}_{i}} \frac{n_{\mathrm{B}, \mathrm{a}_{i+1}}}{n_{\mathrm{C}, \mathrm{a}_{i+1}}}\right) \frac{T_{\mathrm{B}_{i+1}}}{\left(T_{C_{i+1}}\right)^{2}}-a_{\mathrm{C}_{i}} b_{i} \frac{T_{\mathrm{B}_{i+1}}}{\left(T_{C_{i+1}}\right)^{2}}+\frac{a_{\mathrm{B}_{i}}}{T_{\mathrm{B}_{i}}} T_{\mathrm{B}_{i+1}}+\left[\operatorname{Ln}_{\mathrm{C}, \ell_{i}}-\right. \\
& \left.b_{i}\left(R n_{\mathrm{C}_{i}}-a_{\mathrm{C}_{i}}\right)\right] \frac{1}{T_{C_{i+1}}}=0
\end{aligned}
$$

In Eqn. (A21), the following terms can be simplified according to expressions (10a)-(10d).

$$
\begin{gathered}
n_{\mathrm{C}, \mathrm{v}_{i}} \frac{n_{\mathrm{B}, \mathrm{v}_{i+1}}}{n_{\mathrm{C}, \mathrm{v}_{i+1}}}=\frac{\left[\left(n_{\mathrm{B}, \mathrm{v}_{i}}+n_{\mathrm{C}, \mathrm{v}_{i}}\right) n_{\mathrm{C}_{i}}-n_{\mathrm{C}, \mathrm{v}_{i}} \dot{n}_{\mathrm{C}, \mathrm{v} \rightarrow \ell_{i}}\right] T_{C_{i+1}}-b_{i} n_{\mathrm{C}_{i}} n_{\mathrm{C}, \mathrm{v}_{i}}}{b_{i} n_{\mathrm{C}_{i}}+\left(1-\frac{n_{\mathrm{C}} C_{i}}{n_{\mathrm{C}, \mathrm{v}_{i}}}\right) \dot{n}_{\mathrm{C}, \mathrm{v} \rightarrow \ell_{i}} T_{C_{i+1}}}=\frac{b_{\mathrm{v}_{i}} T_{C_{i+1}}-c_{\mathrm{v}_{i}}}{b_{i} n_{\mathrm{C}_{i}}+\left(1-\frac{n_{\mathrm{C}_{i}}}{n_{\mathrm{C}, \mathrm{v}_{i}}}\right) \dot{n}_{\mathrm{C}, \mathrm{v} \rightarrow \ell_{i}} T_{C_{i+1}}} \\
n_{\mathrm{C}, \mathrm{v}_{i}} \frac{n_{\mathrm{B}, \mathrm{v}_{i+1}}}{n_{\mathrm{C}, \mathrm{v}_{i+1}}}=\frac{\left[\left(n_{\mathrm{B}, \mathrm{a}_{i}}+n_{\mathrm{C}, \mathrm{a}_{i} i}\right) n_{\mathrm{C}_{i}}-n_{\mathrm{C}, \mathrm{a}_{i}} \dot{n}_{\mathrm{C}, \mathrm{v} \rightarrow \ell_{i}}\right] T_{C_{i+1}}-b_{i} n_{\mathrm{C}_{i}} n_{\mathrm{C}, \mathrm{a}_{i}}}{b_{i} n_{\mathrm{C}_{i}}+\dot{n}_{\mathrm{C}, \mathrm{v} \rightarrow \ell_{i}} T_{C_{i+1}}}=\frac{b_{\mathrm{a}_{i}} T_{C_{i+1}}-c_{\mathrm{a}_{i}}}{b_{i} n_{\mathrm{C}_{i}}+\dot{n}_{\mathrm{C}, \mathrm{v} \rightarrow \ell_{i}} T_{C_{i+1}}}
\end{gathered}
$$

The sum of these two terms equals to

$$
\begin{aligned}
& n_{\mathrm{C}, \mathrm{v}_{i}} \frac{n_{\mathrm{B}, \mathrm{v}_{i}+1}}{n_{\mathrm{C}, \mathrm{v}_{i+1}}}+n_{\mathrm{C}, \mathrm{v}_{i}} \frac{n_{\mathrm{B}, \mathrm{v}_{i+1}}}{n_{\mathrm{C}, \mathrm{v}_{i+1}}}= \\
& \frac{\left[b_{\mathrm{v}_{i}}+b_{\mathrm{a}_{i}}\left(1-\frac{n_{\mathrm{C}_{i}}}{n_{\mathrm{C}, \mathrm{v}_{i}}}\right)\right] \dot{n}_{\mathrm{C}, \mathrm{v} \rightarrow \ell_{i}}\left(T_{C_{i+1}}\right)^{2}+\left\{b_{i} n_{\mathrm{C}_{i}}\left(b_{\mathrm{v}_{i}}+b_{\mathrm{a}_{i}}\right)-\left[c_{\mathrm{v}_{i}}+c_{\mathrm{a}_{i}}\left(1-\frac{n_{\mathrm{C}_{i}}}{n_{\mathrm{C}, \mathrm{v}_{i}}}\right)\right] \dot{n}_{\mathrm{C}, \mathrm{v} \rightarrow \ell_{i}}\right\} T_{C_{i+1}}-b_{i} n_{\mathrm{C}_{i}}\left(c_{\mathrm{v}_{i}}+c_{\mathrm{a}_{i}}\right)}{\left(1-\frac{n_{\mathrm{C} i}}{n_{\mathrm{C}, \mathrm{v}_{i}}}\right)\left(\dot{n}_{\mathrm{C}, \mathrm{v} \rightarrow \ell_{i}}\right)^{2}\left(T_{C_{i+1}}\right)^{2}+b_{i} n_{\mathrm{C}_{i}}\left(2-\frac{n_{\mathrm{C}}}{n_{\mathrm{C}, \mathrm{v}_{i}}}\right) \dot{n}_{\mathrm{C}, \mathrm{v} \rightarrow \ell_{i}} T_{C_{i+1}}+\left(b_{i} n_{\mathrm{C}_{i}}\right)^{2}}
\end{aligned}
$$

Equation (A21) can be rearranged as the following equation by taking the place of term (A24).

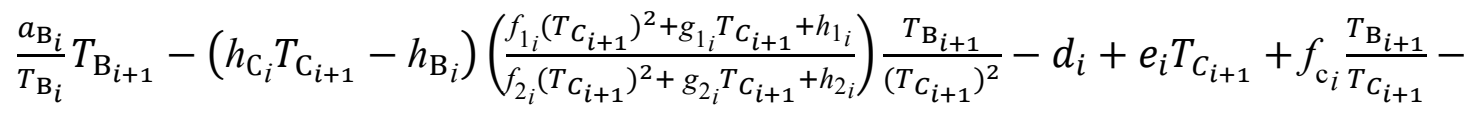

$$
\begin{aligned}
& a_{\mathrm{C}_{i}} b_{i} \frac{T_{\mathrm{B}_{i+1}}}{\left(T_{C_{i+1}}\right)^{2}}+g_{\mathrm{C}_{i}} \frac{1}{T_{C_{i+1}}}=0
\end{aligned}
$$

Replacing $T_{\mathrm{B}_{i+1}}$ using Eqn. (10d) gives

$$
\begin{aligned}
& \frac{a_{\mathrm{B}_{i}}}{T_{\mathrm{B}_{i}}} \frac{p_{\mathrm{B}_{i+1}} V_{\mathrm{B}} T_{\mathrm{C}_{i+1}} \mathrm{C}_{i+1}-p_{\mathrm{C}_{i+1} V_{\mathrm{C}}}}{d_{i}}+d_{i} T_{\mathrm{C}_{i+1}}+f_{\mathrm{c}_{i}} \frac{p_{\mathrm{B}_{i+1}} V_{\mathrm{B}}}{r_{i} T_{\mathrm{C}_{i+1}}-p_{\mathrm{C}_{i+1} V_{\mathrm{C}}}}-a_{\mathrm{C}_{i}} b_{i} \frac{1}{T_{C_{i+1}}} \frac{p_{\mathrm{B}_{i+1}} V_{\mathrm{B}}}{r_{i} T_{\mathrm{C}_{i+1}}-p_{\mathrm{C}_{i+1} V_{\mathrm{C}}}}+g_{\mathrm{C}_{i}} \frac{1}{T_{C_{i+1}}} \\
& -\left(h_{\mathrm{C}_{i}} T_{\mathrm{C}_{i+1}}-h_{\mathrm{B}_{i}}\right)\left(\frac{f_{1 i}\left(T_{\mathrm{C}_{i+1}}\right)^{2}+g_{1 i} T_{\mathrm{C}_{i+1}}+h_{1 i}}{f_{2_{i}}\left(T_{\mathrm{C}_{i+1}}\right)^{2}+g_{2 i} T_{\mathrm{C}_{i+1}}+h_{2 i}}\right) \frac{1}{T_{C_{i+1}}} \frac{p_{\mathrm{B}_{i+1}} V_{\mathrm{B}}}{r_{i} T_{\mathrm{C}_{i+1}}-p_{\mathrm{C}_{i+1}} V_{\mathrm{C}}}=0
\end{aligned}
$$

Multiplying $T_{\mathrm{C}_{i+1}}\left(f_{2_{i}}\left(T_{\mathrm{C}_{i+1}}\right)^{2}+g_{2 i} T_{\mathrm{C}_{i+1}}+h_{2_{i}}\right)\left(r_{i} T_{\mathrm{C}_{i+1}}-p_{\mathrm{C}_{i+1}} V_{\mathrm{C}}\right)$ by each term in Eqn. (A26) gives

$$
\begin{aligned}
& e_{i}\left(T_{\mathrm{C}_{i+1}}\right)^{2}\left(A_{i}\left(T_{\mathrm{C}_{i+1}}\right)^{3}+B_{i}\left(T_{\mathrm{C}_{i+1}}\right)^{2}+C_{i} T_{\mathrm{C}_{i+1}}+D_{i}\right) \\
& -d_{i} T_{\mathrm{C}_{i+1}}\left(A_{i}\left(T_{\mathrm{C}_{i+1}}\right)^{3}+B_{i}\left(T_{\mathrm{C}_{i+1}}\right)^{2}+C_{i} T_{\mathrm{C}_{i+1}}+D_{i}\right) \\
& +g_{\mathrm{C}_{i}}\left(A_{i}\left(T_{\mathrm{C}_{i+1}}\right)^{3}+B_{i}\left(T_{\mathrm{C}_{i+1}}\right)^{2}+C_{i} T_{\mathrm{C}_{i+1}}+D_{i}\right)-G_{i}\left(f_{2_{i}}\left(T_{\mathrm{C}_{i+1}}\right)^{2}+g_{2 i} T_{\mathrm{C}_{i+1}}+h_{2 i}\right) \\
& +E_{i}\left(T_{\mathrm{C}_{i+1}}\right)^{2}\left(f_{2_{i}}\left(T_{\mathrm{C}_{i+1}}\right)^{2}+g_{2 i} T_{\mathrm{C}_{i+1}}+h_{2 i}\right)+f_{\mathrm{c}_{i}} F_{i} T_{\mathrm{C}_{i+1}}\left(f_{2_{i}}\left(T_{\mathrm{C}_{i+1}}\right)^{2}+g_{2 i} T_{\mathrm{C}_{i+1}}+h_{2 i}\right)
\end{aligned}
$$




$$
-h_{\mathrm{C}_{i}} F_{i} T_{\mathrm{C}_{i+1}}\left(f_{1_{i}}\left(T_{\mathrm{C}_{i+1}}\right)^{2}+g_{1_{i}} T_{\mathrm{C}_{i+1}}+h_{1_{i}}\right)+h_{\mathrm{B}_{i}} F_{i}\left(f_{1_{i}}\left(T_{\mathrm{C}_{i+1}}\right)^{2}+g_{1_{i}} T_{\mathrm{C}_{i+1}}+h_{1_{i}}\right)=0 .
$$

By rearrangement,

$$
\begin{aligned}
& e_{i} A_{i}\left(T_{\mathrm{C}_{i+1}}\right)^{5}+\left(e_{i} B_{i}-d_{i} A_{i}+f_{2_{i}} E_{i}\right)\left(T_{\mathrm{C}_{i+1}}\right)^{4} \\
& +\left(e_{i} C_{i}-d_{i} B_{i}+g_{\mathrm{C}_{i}} A_{i}+g_{2_{i}} E_{i}+f_{2_{i}} f_{\mathrm{c}_{i}} F_{i}-f_{1_{i}} h_{\mathrm{C}_{i}} F_{i}\right)\left(T_{\mathrm{C}_{i+1}}\right)^{3} \\
& +\left(e_{i} D_{i}-d_{i} C_{i}+g_{\mathrm{C}_{i}} B_{i}-f_{2_{i}} G_{i}+h_{2_{i}} E_{i}+g_{2_{i}} f_{\mathrm{c}_{i}} F_{i}-g_{1_{i}} h_{\mathrm{C}_{i}} F_{i}+f_{1_{i}} h_{\mathrm{B}_{i}} F_{i}\right)\left(T_{\mathrm{C}_{i+1}}\right)^{2} \\
& +\left(-d_{i} D_{i}+g_{\mathrm{C}_{i}} C_{i}-g_{2_{i}} G_{i}+h_{2_{i}} f_{\mathrm{C}_{i}} F_{i}-h_{1_{i}} h_{\mathrm{C}_{i}} F_{i}+g_{1_{i}} h_{\mathrm{B}_{i}} F_{i}\right) T_{\mathrm{C}_{i+1}} \\
& +\left(g_{\mathrm{C}_{i}} D_{i}-h_{2_{i}} G_{i}+h_{1_{i}} h_{\mathrm{B}_{i}} F_{i}\right)=0
\end{aligned}
$$

Equation (A28) can be obtained by the redefination of the coefficients in Eqn. (A28).

\section{A4 Light extinction in cloud chamber}

The definition of geometric mean $\bar{d}_{\mathrm{pg}}$ and standard deviation $\sigma_{\mathrm{g}}$ used withing the scattering solutions are.

$$
\begin{array}{r}
\bar{d}_{\mathrm{pg}}=\exp \left[\frac{\sum_{j}\left(N_{\mathrm{C}_{f}}^{j} \ln \left(d_{\mathrm{p}_{f}}^{j}\right)\right)}{\sum_{j}\left(N_{\mathrm{C}_{f}}^{j}\right)}\right] \\
\sigma_{\mathrm{g}}=\exp \left[\frac{\sum_{j}\left(N_{\mathrm{C}_{f}}^{j}\left(\ln \left[d_{\mathrm{p}_{f}}^{j}\right]-\ln \left[\bar{d}_{\mathrm{pg}}\right]\right)\right)}{\sum_{j}\left(N_{\mathrm{C}_{f}}^{j}\right)-1}\right]
\end{array}
$$

\section{A5 Temporal response of the cloud chamber}

Growth of monodisperse particle with different initial diameters during the isentropic expansion in the cloud chamber is shown in Fig. A2.
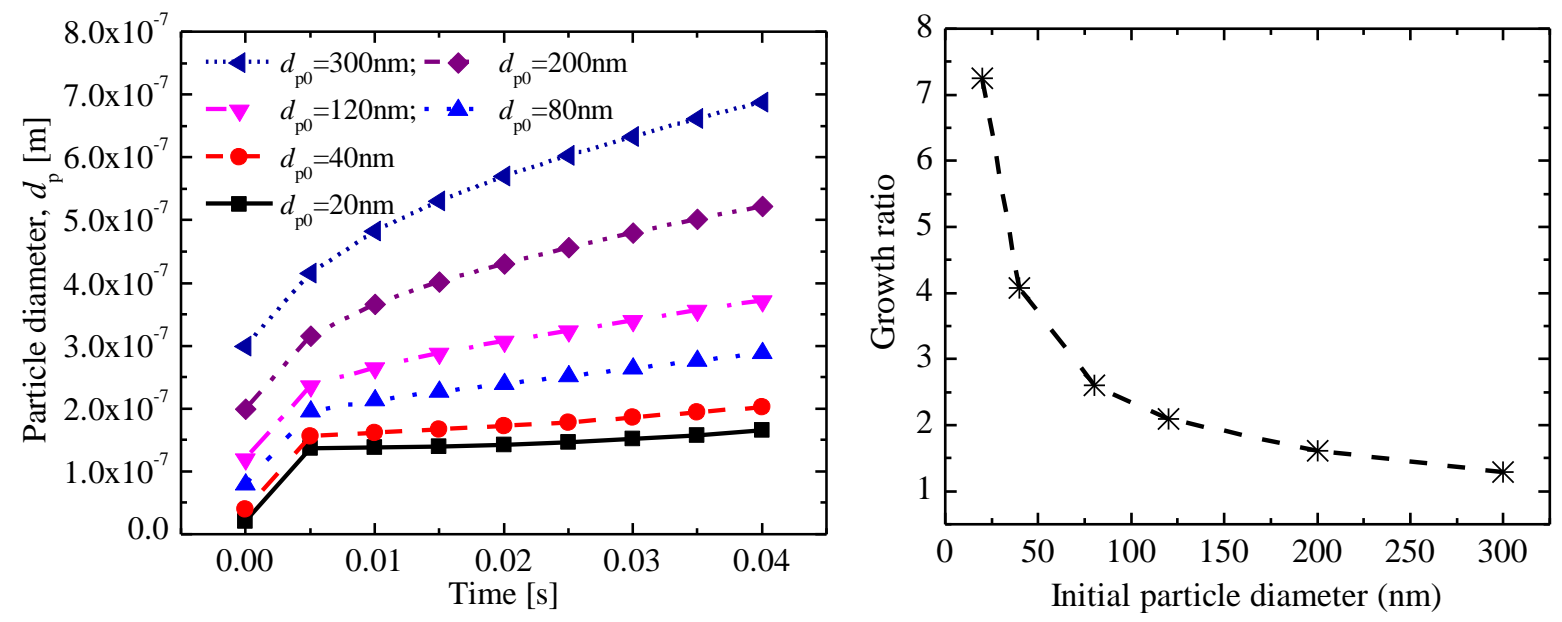

Fig. A2. Growth of monodisperse particles with different initial diameters. 


\section{A6. Values of parameters before and after condensation}

The Number concentration, geometric mean diameter and geometric standard deviation of aerosol particles before and after condensation are given in Table A1.

Table A1. Number concentration, geometric mean diameter and geometric standard deviation before and after condensation.

\begin{tabular}{ccccccc}
\hline \multicolumn{3}{c}{ Before condensation } & & \multicolumn{3}{c}{ After condensation } \\
\cline { 1 - 4 }$N\left(\times 10^{12} / \mathrm{m}^{3}\right)$ & $\bar{d}_{\mathrm{pg}}(\mathrm{nm})$ & $\sigma_{\mathrm{g}}$ & & $N\left(\times 10^{12} / \mathrm{m}^{3}\right)$ & $\bar{d}_{\mathrm{pg}}(\mathrm{nm})$ & $\sigma_{\mathrm{g}}$ \\
\hline 9.51 & 71.3 & 1.74 & & 8.97 & 281.59 & 1.36 \\
9.64 & 70.5 & 1.74 & & 9.09 & 279.93 & 1.36 \\
5.20 & 66 & 1.79 & & 4.91 & 274.24 & 1.36 \\
1.83 & 57.7 & 1.82 & & 1.72 & 258.76 & 1.36 \\
0.65 & 61.7 & 1.85 & & 0.62 & 269.17 & 1.37 \\
0.33 & 66.2 & 1.79 & & 0.31 & 278.12 & 1.36 \\
39.00 & 61.2 & 1.8 & & 36.83 & 243.6 & 1.40 \\
30.90 & 59.7 & 1.8 & & 29.19 & 245.47 & 1.39 \\
23.70 & 60.7 & 1.77 & & 22.33 & 251.37 & 1.37 \\
13.30 & 61.2 & 1.75 & & 12.53 & 258.4 & 1.34 \\
1.43 & 67.6 & 1.76 & & 1.35 & 280.02 & 1.35 \\
0.28 & 64.3 & 1.77 & & 0.27 & 273.64 & 1.35 \\
11.80 & 68.4 & 1.72 & & 11.18 & 273.57 & 1.35 \\
7.36 & 61.7 & 1.77 & & 6.95 & 263.46 & 1.35 \\
17.40 & 74.9 & 1.71 & & 16.37 & 282.84 & 1.36 \\
7.03 & 76.3 & 1.74 & & 6.64 & 294.14 & 1.37 \\
2.68 & 73.9 & 1.77 & & 2.53 & 292.95 & 1.37 \\
1.21 & 74.8 & 1.77 & & 1.14 & 296.24 & 1.37 \\
3.03 & 68.9 & 1.8 & & 2.86 & 282.25 & 1.37 \\
5.95 & 71.1 & 1.77 & & 5.61 & 284.2 & 1.37 \\
10.70 & 71.8 & 1.74 & & 10.13 & 281.82 & 1.36 \\
7.15 & 86.1 & 1.72 & & 6.74 & 313.75 & 1.37 \\
3.30 & 85.2 & 1.75 & & 3.11 & 316.45 & 1.38 \\
1.02 & 82.7 & 1.71 & & 0.96 & 312.47 & 1.36 \\
41.10 & 85.2 & 1.67 & & 38.74 & 283.26 & 1.40 \\
20.30 & 84.4 & 1.71 & & 19.12 & 281.59 & 1.39 \\
\hline
\end{tabular}

